\title{
Design of fluorescent materials for chemical sensing
}

\section{Lourdes Basabe-Desmonts, David N. Reinhoudt and Mercedes Crego-Calama*}

\author{
Received 10th October 2006 \\ First published as an Advance Article on the web 2nd February 2007 \\ DOI: $10.1039 / b 609548 h$
}

There is an enormous demand for chemical sensors for many areas and disciplines. High sensitivity and ease of operation are two main issues for sensor development. Fluorescence techniques can easily fulfill these requirements and therefore fluorescent-based sensors appear as one of the most promising candidates for chemical sensing. However, the development of sensors is not trivial; material science, molecular recognition and device implementation are some of the aspects that play a role in the design of sensors. The development of fluorescent sensing materials is increasingly captivating the attention of the scientists because its implementation as a truly sensory system is straightforward. This critical review shows the use of polymers, sol-gels, mesoporous materials, surfactant aggregates, quantum dots, and glass or gold surfaces, combined with different chemical approaches for the development of fluorescent sensing materials.

Representative examples have been selected and they are commented here.

\section{Introduction}

Chemical sensing refers to the continuous monitoring of the presence of chemical species. ${ }^{1}$ It is hardly necessary any longer to stress the importance of the development of new chemical sensors. Many disciplines need sensing systems, including chemistry, biology, clinical biology and environmental science.

Department of Supramolecular Chemistry and Technology, MESA Institute for Nanotechnology, University of Twente, P. O. Box 217, 7500 AE Enschede, The Netherlands
For example, analytical methods to study the cell chemistry and to understand the mechanisms that make cells work are highly desirable. Therefore, sensors for biomolecules such as neurotransmitters, glutamate and acetylcholine, glycine, aspartate and dopamine, NO and ATP would be very helpful. ${ }^{2}$ Along the same line it is interesting to develop sensors for metal ions such as sodium, potassium, and calcium which are involved in biological processes such as transmission of nerve pulses, muscle contraction and regulation of cell activity. Interesting as well is the detection of aluminium which is toxic and whose possible implication in Alzheimer's disease is being

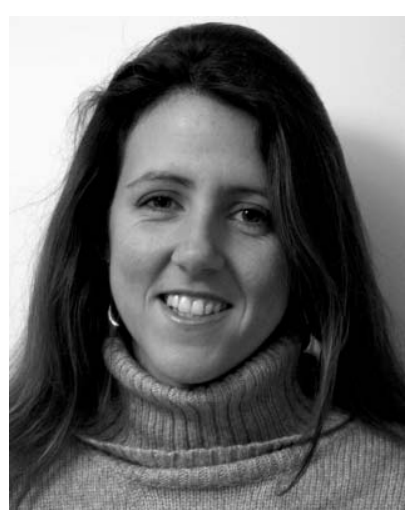

Lourdes Basabe-Desmonts
Lourdes Basabe-Desmonts studied chemistry at the Universidad Autonoma de Madrid (Spain) from 1996 to 2001. In October 2001 she joined the Supramolecular Chemistry and Technology Group at the University of Twente directed by Prof. D. N. Reinhoudt, where she worked as a PhD student under the guidance of $\mathrm{Dr}$ Mercedes Crego-Calama until January 2006. Her PhD was focused in the development of fluorescent self-assembled monolayers on glass as new sensing materials. At present she is working as a postdoctoral researcher with Dr. Luke Lee at the Biomedical Diagnostics Institute in Dublin City University (Ireland). Her current research aims at the development of new functional microfluidic devices for medical diagnostics.

Professor David N. Reinhoudt was born in 1942 in The Netherlands. He studied Chemical Technology at the Delft University of Technology and graduated (suma cum laude) in chemistry in 1969 with Professor H. C. Beijerman. In the period 1970-1975 he worked at Shell where he started the crown ether

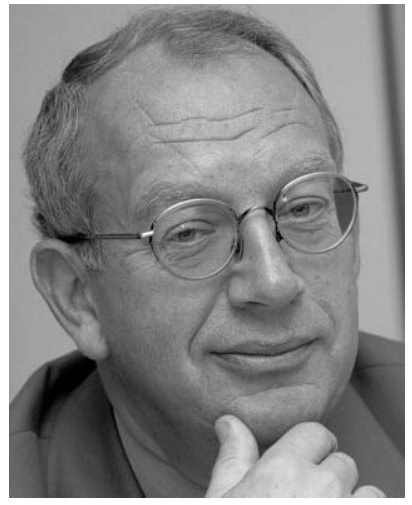

research program. In 1975 he was appointed as a part-time professor (extraordinarius) at the University of Twente followed by the appointment as a full professor in 1978. The major part of his research deals with supramolecular chemistry and technology. Nanotechnology, molecular recognition, and non-covalent combinatorial synthesis are the major fields. Application of supramolecular chemistry e.g. in "lab-on-a-chip", in the field of electronic or optical David N. Reinhoudt sensor systems, catalysis, and molecular materials. Professor Reinhoudt is the scientific director of the $\mathrm{MESA}^{+}$Research Institute. Since 2002 he is the chairman of the Board of NanoNed, the Dutch Network for Nanotechnology He is a member of the Royal Dutch Academy of Sciences, Fellow of the American Association for the Advancement of Science, and Fellow of the Institute of Physics. He is the author of more than 800 scientific publications, patents, review articles, and books. He has been honored with the Izatt-Christensen award (1995), the Simon Stevin Mastership (1998) and Knight of the Order of the Dutch Lion (2002). 
discussed. In the field of environmental science, it is well known that mercury, lead and cadmium are toxic for living organisms, and thus early detection in the environment is desirable. Additionally, sensors for explosives and hazardous chemicals are being extensively investigated for the detection of landmines ${ }^{3}$ and warfare chemicals. With the war on terrorism, the need for accurate, reliable, real-time biological and chemical sensing is in the spotlight. ${ }^{4,5}$ Finally, chemical sensing allows for the study and control of chemical processes from the laboratory to the industrial scale, and plays an important role in the food industry for the control of food quality and safety. ${ }^{6}$

The list of interesting analytes to be detected is lengthy ${ }^{2}$ and there is a need for rapid and low-cost testing methods for a wide range of clinical bioprocesses and in areas of chemical and environmental applications. ${ }^{7}$ On the other hand it has been pointed out before that there is a large gap between the importance of certain types of organic molecules and the availability of sensors for these target compounds. This is probably due to a communication gap between the communities that need chemosensors and those that might fabricate them. ${ }^{8}$ Thus it is important to expand the range of analytes that can be detected and quantified. In the case of biomolecules, nature provides us with a large number of specific interactions that can be used for biosensors. However, there are also a large number of molecules that are not easily detectable; therefore new artificial probes must be designed. ${ }^{8}$

Many features make fluorescence one of the most powerful transduction mechanisms ${ }^{9}$ to report the chemical recognition event. A number of fluorescence microscopy and spectroscopy techniques based on the life-time, anisotropy or intensity of the emission of fluorescent probes have been developed over the years. ${ }^{10}$ These are enormously sensitive techniques that allow even the detection of single molecules. Fluorescence does not consume analytes and no reference is required. Light can travel without physical wave-guide, facilitating enormously the

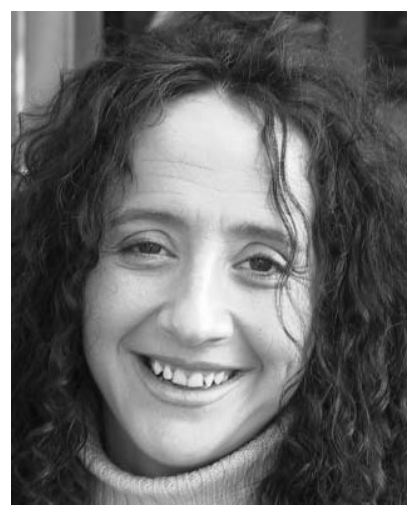

Mercedes Crego-Calama

Mercedes Crego Calama was born in Salamanca, Spain. Here, she received her Master degree (1991) and her PhD (Cum Laude) in Chemistry (1995) with J. R. Moran. In 1995, she moved to University of Pittsburgh, USA (NATO fellowship) to collaborate with A. D. Hamilton. In 1997 she was awarded with a Marie Curie European postdoctoral fellowship and she moved to the University of Twente, The Netherlands where she worked with D. N. Reinhoudt on dynamic combinatorial libraries. In 2000, she became Researcher of the Royal Dutch Academy of Sciences (KNWA) working on combinatorial sensor fabrication. Alongside her KNWA duties, she currently holds a tenured position as Universiteit Hooft Docent in the University of Twente. Her current research interests, besides in glass microarrays, are in the design and fabrication of nanostructures via self-assembly and self-organization. technical requirements. ${ }^{11}$ Additionally with fluorescence it is possible to perform remote monitoring. For example, it is possible to monitor simultaneously concentrations of the target analytes in all regions of a living cell. ${ }^{12}$ An advantage of fluorescence spectroscopy is that different assays can be designed based on different aspects of the fluorescence output (lifetime, intensity, anisotropy and energy transfer). ${ }^{11,13}$ Additionally, laser fiber optics and detection technologies are well established. Therefore, fluorescence techniques are envisioned as the most important future detection method for miniaturized ultra-high-throughput screening. ${ }^{13}$

Chemical sensing using fluorescence to signal a molecular recognition event was first demonstrated during the early 1980s when Tsien et al. reported the synthesis of the first fluorescent calcium indicators. ${ }^{14,15}$ They are based on calcium ion chelate receptors, covalently linked to simple aromatics rings or other dyes as chromophores. Since then an enormous amount of work has been done for the rational design of fluorescent indicators. ${ }^{16-20}$ However, only few sensors are currently available because the implementation of sensing probes in functional devices without the loss of sensitivity is still very challenging.

Previously the habit of organic chemists to refer to new molecular indicators as "sensors" has been criticized since only by the integration of such fluorescent indicators into a device a sensor will be obtained. ${ }^{21}$ To avoid such confusion, Czarnik introduced the concept of "Chemosensor" in 1993. ${ }^{22,23} \mathrm{~A}$ chemosensor was defined as: "A compound of abiotic origin that complexes to an analyte reversibly with a concomitant fluorescent signal transduction" and it constitutes only the active transduction unit of a sensor. ${ }^{22,23}$ As a consequence of the development of molecular chemosensors, extensive efforts are being done at the moment in the realization of materials for fluorescent sensing. New approaches based on materials in which molecular indicators are already integrated are increasingly captivating the attention of the scientists because its implementation as a truly sensory system is more straightforward. Nevertheless, in many cases and especially in polymer based sensors, the design of new sensing materials has been based on the availability of new receptors, rather than chemosensors. $^{24}$

The strategies and ideas that chemists have developed for new fluorescent chemosensing materials and the integration of the sensory system in sensor devices are reviewed here. The review focuses mainly on the work done during the last 10 years. Fluorescent sensors are divided in two groups, fluorescent biosensors and fluorescent chemosensors. ${ }^{25}$ Even though biosensors ${ }^{26}$ represent a very important area in sensing ${ }^{27,28}$ they fall outside of the scope of this review. This review will be limited to the development of chemosensors based on new artificial materials that are able to signal reversibly the presence of other chemical species. Nevertheless, due to the fact this field is very broad, it is very difficult to give a detailed overview of every publication that has appeared in literature. None the less, all the information about the subject is included, sometimes by references to other reviews which are an exhaustive overview of a specific material type. Additionally, new trends in the development of fluorescent sensors such as the fabrication of nanosensors, ${ }^{29}$ the use of 
combinatorial methods and the fabrication of high density sensor arrays ${ }^{3}$ will be also briefly discussed.

\section{Classical design of fluorescent indicators}

The classical design of a fluorescent indicator includes two moieties, a receptor responsible for the molecular recognition of the analyte and a fluorophore responsible of signaling the recognition event. There are three main strategies to approach the design of fluorescent molecular indicators for chemical sensing in solution. The first results in intrinsic fluorescent probes, ${ }^{30,31}$ which are fluorescent molecules where the mechanism for signal transduction involves interaction of the analyte with a ligand that is part of the $\pi$-system of the fluorophore. The second are extrinsic fluorescent probes, in which the receptor moiety and the fluorophore are covalently linked but are electronically independent. ${ }^{30,32-34}$ The extrinsic probes have also been denoted conjugate ${ }^{35}$ nevertheless, for homogeneity reasons, we prefer to call then "extrinsic" 22,23 In this case, different receptor molecules might be synthesized and afterwards attached to a fluorophore to make the sensitive probe. Due to the covalent linking through a spacer both moieties are in close proximity; the interaction of the analyte with the receptor induces a change in the fluorophore surroundings and changes its fluorescence. The third strategy is called chemosensing ensemble, based on a competitive assay in which a receptor-fluorophore ensemble is selectively dissociated by the addition of an appropriate competitive analyte able to interact efficiently with the receptor resulting in a detectable response of the fluorophore. ${ }^{36-40}$

\section{Fluorescent materials for chemical sensing}

After the production of a fluorescent indicator the next step toward the fabrication of a sensor is usually the production of the sensing material by the incorporation of the indicator in a solid support. Until now the most common approach for the immobilization step is the physical entrapment of the sensitive probe in a polymer matrix. ${ }^{41}$ After the entrapment the polymer is deposited on a device such as an optical fiber or the surface of a waveguide to create the working sensor. However, physical entrapment of the dyes in the polymer matrix produces inhomogeneity in the material and gives stability problems due to the leaching of the fluorescent probe, reducing the lifetime and reproducibility of the sensor. Thus, despite the easy preparation of these materials, they are rarely incorporated into commercial instruments. To improve the stability of these materials, the alternative is the covalent attachment of the probes to the polymeric matrices. ${ }^{42}$ Parallel to the production of polymeric materials, new trends in material science for chemical sensing are emerging. Other materials have been developed where the components of a sensing system (receptor and fluorophore) are directionally confined in a physical space, i.e. they are covalently immobilized at a surface or form surfactant aggregates. A number of materials such as silica particles, ${ }^{43}$ glass and gold surfaces, ${ }^{44}$ quantum dots, ${ }^{45}$ Langmuir-Blodgett films, ${ }^{46}$ vesicles, ${ }^{47}$ liposomes, ${ }^{48}$ and others ${ }^{49}$ are used combined with many chemical receptors to create sensitive fluorescent materials.

\subsection{Fluorescent polymers}

Polymers are still the most common support for chemical sensors. They are convenient due to the fact that they are easily processable to small particles and thin films that can be deposited onto optical fibers, ${ }^{50}$ and waveguides ${ }^{51,52}$ for sensor fabrication. During the last two decades chemical indicators have been immobilized in polymeric matrices mainly by simple impregnation, ${ }^{3}$ by doping ${ }^{53}$ or by covalent attachment. ${ }^{54}$ Other strategies such as electrostatic layer-by-layer assembly have also been used. ${ }^{55}$ Polymers used in sensor devices either participate in the sensing mechanism or they are used to immobilize the component responsible for analyte sensing. ${ }^{56}$ The use of polymers for different physical, chemical and biochemical sensing applications have been recently reviewed by Adhikari and Majumdar. ${ }^{56}$

Physical entrapment of the dyes in the polymer matrix is the simplest method for immobilization of dyes and indicators into polymer materials. In general these methods produce unstable materials because leaching of the probes limits their use for long time monitoring. Nevertheless, this method is widely used for the preparation of sensitive thin films or microspheres. ${ }^{57,58}$ Polymeric thin films with embedded organic dyes are also very often immobilized on the tip of optical fibers to perform the sensing measurements. ${ }^{59}$ The specific incorporation of fluorescent probes in polymers has been recently reviewed by Bosch et al. ${ }^{60}$ Entrapment of organic dyes and transition metal complexes has also been used to design probes for sensing $\mathrm{O}_{2}{ }^{57,61}$ Yang and co-workers recently reported the immobilization of pyrene-labeled metalloporphyrins in a plastized poly(vinyl chloride) (PVC) membrane for the sensing of imidazole derivatives such as histidine. ${ }^{62}$ Approaches based on dye-doped thin films have been used in the analysis of organic vapors, ${ }^{63-65}$ the detection of metal ions, ${ }^{66-68}$ and the determination of $\mathrm{pH} .{ }^{69,70}$

Processing of polymers can also yield polymeric particles with sizes ranging from nanometers to micrometers. These particles are easily transformed into sensing systems by simply staining them with dye molecule solutions. ${ }^{71-74}$ Because sensing particles can act as an individual probe, they can easily be used for the fabrication of sensor arrays. ${ }^{58}$ Their small size and their polymeric nature make them suitable candidates for the generation of micro or nanosensors for intracellular analysis. ${ }^{75,76}$ The production of sensor arrays and nanosensors by incorporation of dye molecules into polymeric particles will be discussed later.

As an alternative for dye-impregnated polymers, fluorescent polymers have been synthesized. Covalent attachment of the fluorescent molecules into polymeric materials is possible after polymerization if the polymer contains reactive functional groups, ${ }^{77}$ or by co-polymerization with a fluorescent polymerizable monomer. ${ }^{54}$ Initially, covalent functionalization of polymers with fluorescent molecules was performed by covalent attachment of fluorophores to natural polymers as cellulose. For example, in 1992 Wolfbeis et al. already reported the immobilization of $\mathrm{pH}$ sensitive dyes in cellulose matrices, ${ }^{78}$ and recently Ueno's group described the covalent immobilization of dansyl functionalized cyclodextrins in a cellulose membrane for the detection of neutral molecules (Fig. 1). ${ }^{79,80}$ 


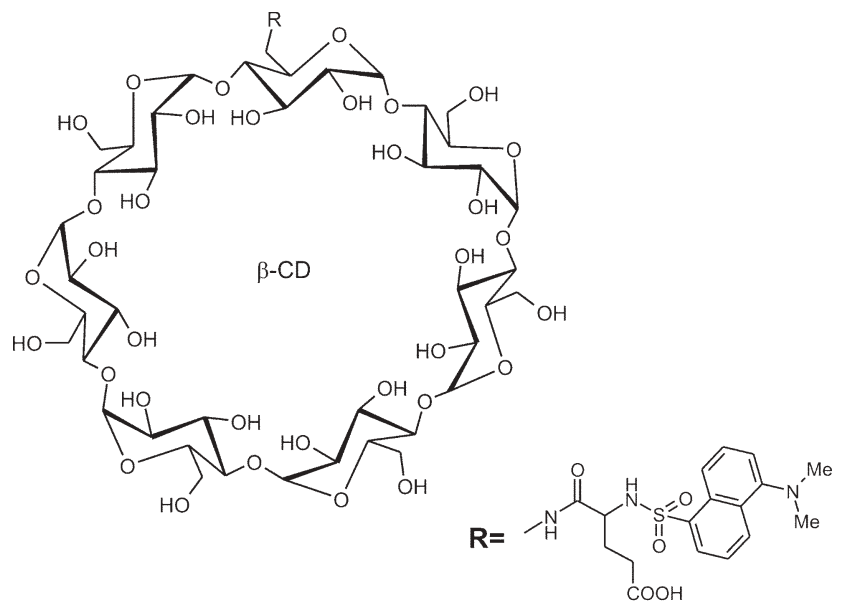

DnsGlu- $\beta-C D$

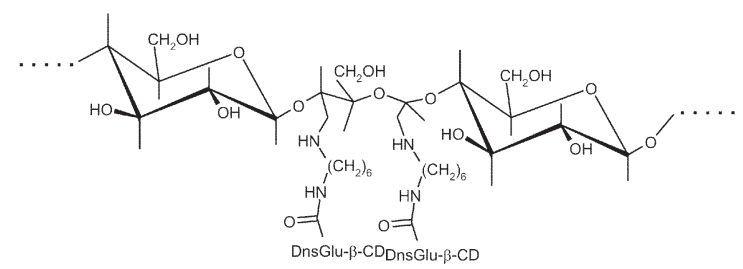

DnsGlu- $\beta$-CD-membrane

Fig. 1 Structure of a dansyl glutamate-modified $\beta$-cyclodextrins (DnsGlu- $\beta-C D$ ), which can be subsequently immobilized in a cellulose membrane (DnsGlu- $\beta$-CD-membrane). (Reprinted with permission from ref. 80. Copyright 2001, American Chemical Society.)

Depending on properties such as permeability, polarity, mechanical strength, biocompatibility and solubility of the different polymers they are suitable for the use in different media and for different analytes. Synthetic polymers with specific functionalities are used nowadays for the production of specific sensors. A large variety of probes containing covalently linked dyes have been developed. Barnard and Walt published in $1991^{81}$ the photopolymerization of appropriate dye indicators on the surface of an imaging fiber tip for $\mathrm{pH}$, $\mathrm{CO}_{2}$ and $\mathrm{O}_{2}$ sensing. ${ }^{82}$ They also reported the covalent attachment of fluorophores to the surface of silica, poly(methyl)styrene, and poly(ethylene glycol) (PEG) microspeheres $^{58,83}$ to generate a collection of small sensors that afterwards could be used for the fabrication of sensor arrays on the tips of optical fibers for organic vapors ${ }^{3}$ and DNA detection. ${ }^{84}$ An optical fiber coated with a fluorescent membrane containing anthracene has been reported for the sensing of tetracycline antibiotics by $\mathrm{Yu}$ and co-workers ${ }^{85} \mathrm{An}$ anthracene functionalized polymer has been recently used for the selective sensing of metalloproteins by energy transfer process. ${ }^{86}$ Anslyn's group has used poly(ethylene glycol)polystyrene (PEG-PS) resin beads derivatized with a variety of indicator molecules to generate an array of microsize $\mathrm{pH}$ sensors. ${ }^{87}$ Wolfbeis and co-workers have shown the coimmobilization of transition metal complexes and $\mathrm{pH}$ indicators in a hydrogel matrix to design a $\mathrm{pH}$ sensor with long luminescence decay times. ${ }^{88}$ Polymers labeled with naphthalimide are sensitive to transition metal ions and $\mathrm{pH}^{89}$ Recently

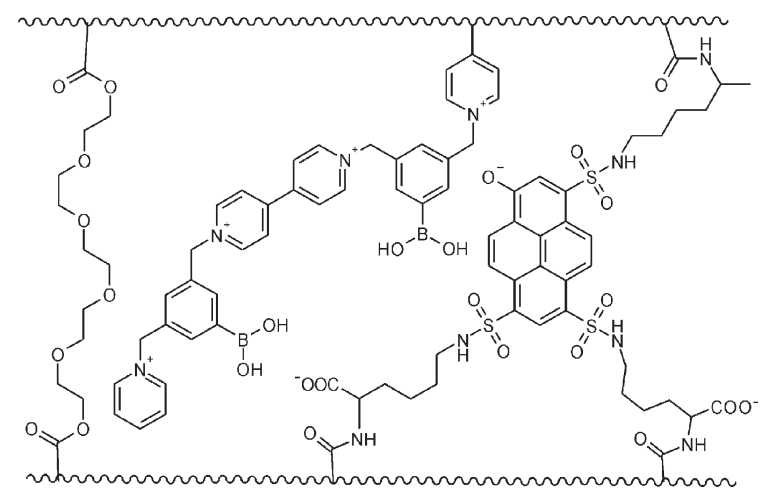

Fig. 2 Glucose-sensing polymer based in boronic acids and pyrene derivates, which are in close proximity due to electrostatic interactions. (Adapted from ref. 54.)

a fluorescent hydrogel thin film sensitive to $\mathrm{pH}$, has been prepared by copolymerization of a modified dye and poly(ethylene glycol) diacrylate. ${ }^{90}$ Using a similar strategy a new commercial optical sensor for glucose, under physiological conditions, has been developed by the group of Singaram. ${ }^{54}$ They used boronic acid derivatives together with a fluorophore derivative to form a thin film hydrogel. Boronic acids are known to bind glucose reversibly under physiological conditions. They specifically combined a cationic boronic-acid (a functional quencher) and an anionic dye (Fig. 2). The electrostatic interactions between both produce a quenching of the fluorescence of the dye which is modulated upon interaction between the boronic acid and the glucose.

The cooperative action between artificial receptors and a supramolecular hydrogel has been proven to be very useful also for the sensing of phosphate derivatives. ${ }^{91}$

Another approach involving boronic acids for the recognition of sugars was reported by Rivero and co-workers. ${ }^{92}$ They immobilized dansylphenylboronic acid in polymeric microspheres for the recognition of fructose.

One of the most successful fluorescent materials for chemical sensing developed to date has been the fluorescent sensor for potassium by He et al. They developed a sensor for the measurement of extracellular potassium in blood. It is a photoinduced electron transfer (PET) type fluoroionophore, based on a cryptand binding site covalently linked onto a polymeric solid support. The material shows a strong aqueous binding of potassium in the $\mathrm{mM}$ range, good selectivity against other extracellular cations such as sodium and calcium and large fluorescent signal response. The excitation and emission wavelengths are $>400 \mathrm{~nm}$ and the emission is $>500 \mathrm{~nm}$. These are important characteristic for sensors that must be used in whole blood measurements. The sensor is now commercialized as part of the Roche OPTICCA portable blood optical analyzer. ${ }^{93}$

A special case of polymeric fluorescent systems are luminescent dendrimers which can also be seen as nanosensors (see sections 3.6 and 3.7). These are macromolecules with a well-defined chemical structure in which chemical units can be easily included for the recognition of ions or neutral molecules (Fig. 3). Luminescent dendrimers have been recently reviewed by Balzani et al ${ }^{94}$ Dendritic structures containing luminescent 


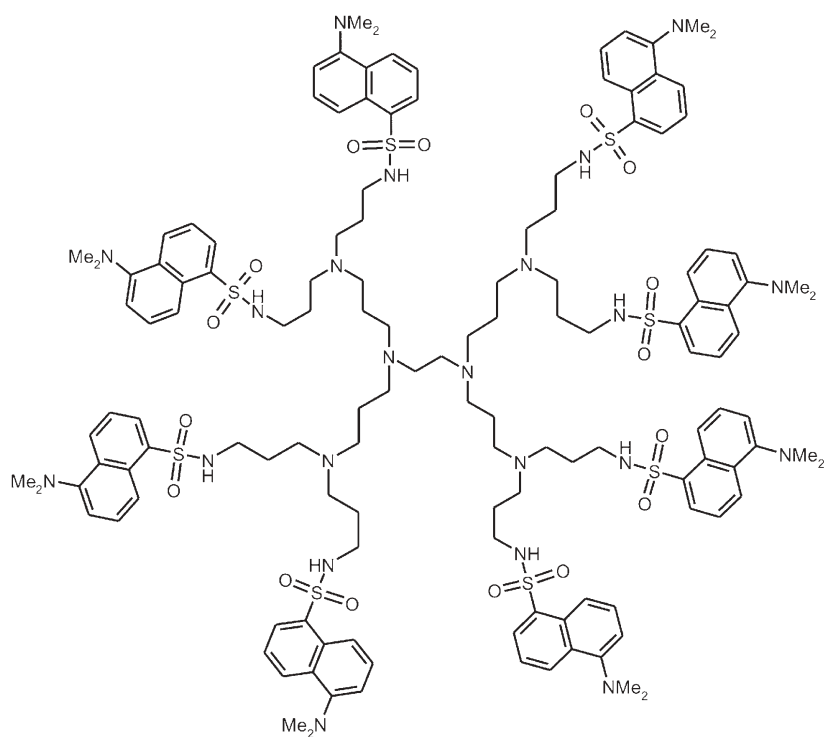

Fig. 3 Structure of a dansyl dendrimer sensitive to the presence of $\mathrm{Co}^{2+}$ ions. (Adapted from ref. 99.)

metal complexes, fluorescent organic chromophores, porphyrins and fullerenes have been reported. ${ }^{94}$ Signal amplification processes in these dendrimers have been well characterized ${ }^{95}$ and could be advantageous for sensor design. In the field of chemical sensing, it has been demonstrated that luminescent dendrimers could be used for chiral amino alcohols, ${ }^{96-98}$ and metal ion sensing. ${ }^{95,99-101}$

3.1.1 Molecular imprinted polymers. A special case of fluorescent polymers are fluorescent molecular imprinted polymers. ${ }^{102}$ Molecular imprinting used already in 1949 by Dickey, ${ }^{103}$ is one of the strategies that offer a synthetically efficient route to artificial receptors. It is a very interesting approach for the fabrication of new fluorescent sensitive probes because it does not require the exact prior knowledge of the three-dimensional structure of the target molecule and the complete synthesis of a receptor. Ideally this method could be used for the detection of a wide range of compounds. The imprinting process involves the co-polymerization of functional monomers and a cross-linker in the presence of target analytes which act as a molecular template (imprint molecule). The functional monomer initially forms a complex with the imprint molecule, and following polymerization, their functional groups are held in position by the highly cross-linked polymeric structure. After removal of the imprinted molecule a cavity is formed that is complementary in size and shape to the analyte. The cavity is also lined with a complementary functionality, which is provided by the functional monomer.
In this way the polymer has now a "molecular memory" and exhibits specific binding characteristics for the template and structurally related compounds (Fig. 4).

The recognition properties of MIPs have been combined with a variety of transducers to generate different sensors such as capacitance sensors and sensors based on mass-sensitive acoustic or conductimetric transduction, ellipsometry, surface plasmon resonance, etc. ${ }^{104}$ Competitive binding based sensors have also been described for these types of polymers. ${ }^{104}$ In 1997 the first example where fluorescent reporter groups were incorporated into the MIP appeared. ${ }^{104-106}$ Upon binding to the imprinted binding sites the analyte interacts with the fluorescent molecules and their fluorescence is quenched. Powell and co-workers reported the synthesis of a polymer imprinted with cyclic adenosine monophosphate (cAMP) using the fluorescent monomer trans-4- $[p-(N, N$-dimethylamino $)$ styryl]- $N$-vinylbenzylpyridinium chloride. ${ }^{105}$ In this way, the fluorophore is part of the created recognition site and is quenched upon complexation of the cAMP in water.

In the last five years several reports have appeared where intrinsically fluorescent imprinted polymers have been used for sensing of L-tryptophan, ${ }^{107}$ cyclic GMP, ${ }^{108}$ histamine, ${ }^{109}$ cyclic AMP, ${ }^{105}$ D-fructose, ${ }^{110}$ creatinine $^{111}$ and other analytes. ${ }^{108,112-116}$ Normally in these systems, recognition of the analytes results in the quenching of the fluorescence emission. However, in sensor design enhancement of the signal is more desirable. Recently, a new fluorescent imprinted polymer that responds to the binding event with a high enhancement in fluorescence intensity has been reported by Takeuchi and co-workers. ${ }^{117}$ The co-polymerization of ethylene glycol dimethylacrylate, cross-linker, and the functional monomer 2-acrylamidoquinoline (1) (Fig. 5) in presence of cyclobarbital (2) yields a fluorescent hydrogen-bonded polymer able to bind selectively to the imprinted analyte. Cyclobarbital showed higher affinity to the imprinted polymer than two structurally related compounds (3 and $\mathbf{4}$ ) having the same two-point hydrogen-bonding pattern to the functional monomer 1.

One of the advantages of these systems is the easy synthesis. However, this is offset by the relatively poor overall affinity and selectivity. It is believed that only part of the created binding sites have high affinity and selectivity for the template molecule. $^{42}$ Despite their poor selectivity, MIPs are suitable candidates to be used in sensor arrays where the collection of responses of these unspecific sensors to the presence of an analyte can create a characteristic pattern for analyte recognition. ${ }^{118}$

3.1.2 Conjugated polymers. A different type of fluorescent polymers is the so-called conjugated polymers (CP).

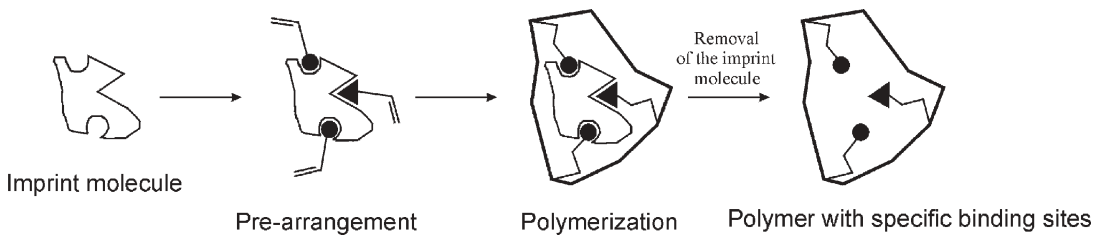

Fig. 4 Schematic representation of the polymer imprinting process showing one binding site within the polymer matrix. 
<smiles>C=CC(=O)Nc1ccc2ccccc2n1</smiles>

1

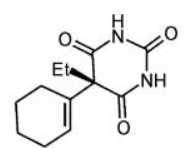

2

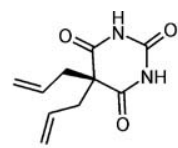

3

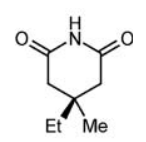

4

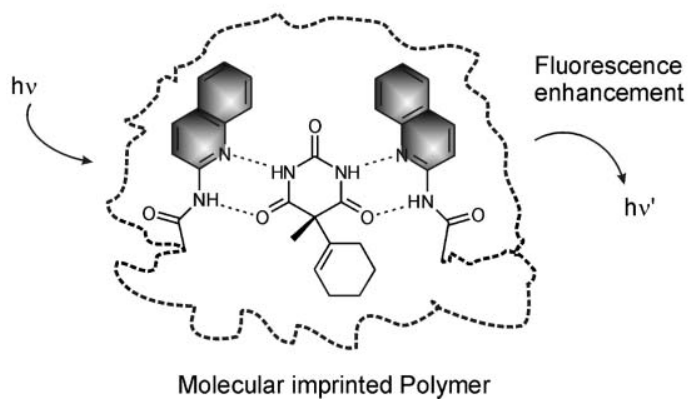

Fig. 5 Chemical structures of the functional monomer 2-acrylamidoquinoline (1), cyclobarbital (2), the structural related compounds allobarbital (3) and 3-ethyl-3-methylglutarimide (4), and a schematic representation of one binding site of the cyclobarbital imprinted polymer. (Adapted from ref. 117).

Conjugated polymers are polyunsaturated compounds with alternating single and double bonds along the polymer chain in which all backbone atoms are $\mathrm{sp}$ - or $\mathrm{sp}^{2}$-hybridized. This electronic conjugation between each repeat unit creates a semiconductive "molecular wire". The resulting interaction between orbitals creates a semiconductor band structure having a valence band (filled with electrons) and a conduction band (devoid of electrons). The semiconductive nature of these organic polymers gives them very useful optical and optoelectronic properties. Fig. 6 shows the structure of some representative conjugated polymers.

The group of Swager demonstrated in 1995 that "wiring molecular recognition sites in series" leads to ultra-high sensitivity. ${ }^{119,120}$ This sensitivity arises from the collective optical and conducting properties of the CP. These polymers are extremely sensitive to minor external structural perturbations or to electron density changes within the polymer, due to their ability to self-amplify their fluorescence quenching response upon perturbation of the electronic network upon binding of analytes. Depending on the system, a CP can exhibit a strong luminescence, the luminescence efficiency is related to the delocalization and polarization of the electronic

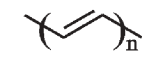

Polyacetylene<smiles>[R]n1c(C)ccc1C</smiles>

$\mathrm{R}=\mathrm{H}$, Polypyrrole $\mathrm{R}=\mathrm{CH}_{3}$, Poly $(\mathrm{N}-$ methyl pyrrole $)$<smiles>CCc1ccc(NC)cc1</smiles>

Polyaniline

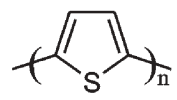

Polythiophene
Fig. 6 Chemical structures of some representative conjugated polymers.

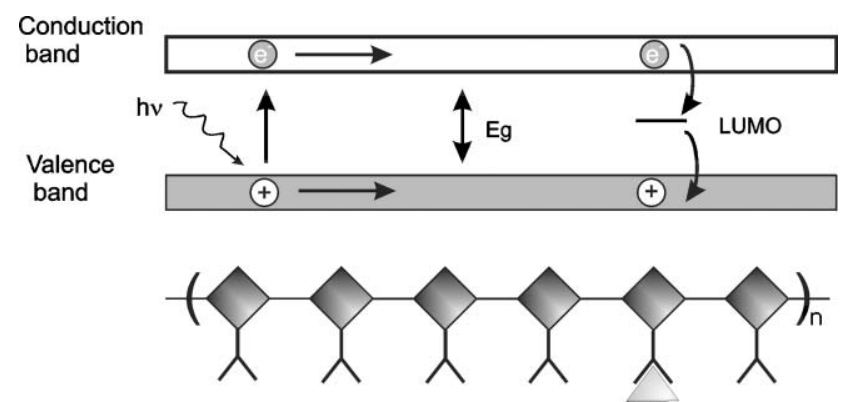

Fig. 7 Band diagram illustrating the mechanism for exciton transport and electron transfer fluorescence quenching of a conjugated polymer upon interaction with the analyte.

structure. These polymers are good candidates as materials for fluorescent sensing. Fig. 7 shows schematically how conjugated polymers amplify the molecular recognition signal via migration of electrons along the polymer chain. It shows a basic band diagram illustrating the mechanism known as photoinduced electron transfer fluorescence quenching. Irradiation of the polymer with a photon causes promotion of an electron to the conduction band (which is now of a much higher energy), which then migrates along the polymer backbone. Analyte binding produces a trapping site whereby the excitation is effectively deactivated by electron transfer quenching. The low energy LUMO can in an exergonic process accept the electron from the excited state of the polymer. This destroys the polymer based excited state, and the polymer can not longer fluoresce. The final step of reverse electron transfer from the quencher's LUMO to the polymer valence band is a non-radiative process.

Fig. 8 compares schematically the $\mathrm{CP}$ and the classical chemosensor approach. Whereas complete fluorescence quenching would be observed in the case of the conjugated polymer upon interaction with an analyte, in the case of nonconjugated sites exposed to the same analyte concentration only a small percentage of quenching would be observed. Each analyte is confined to its particular molecule and can only sample one binding site. Therefore, the emission is observed from those molecules which did not bind an analyte. In the CP approach one single interaction can quench a large number of fluorophores and the signal obtained in the presence of the analyte is amplified.

a)

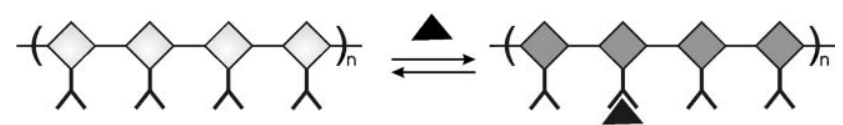

b)

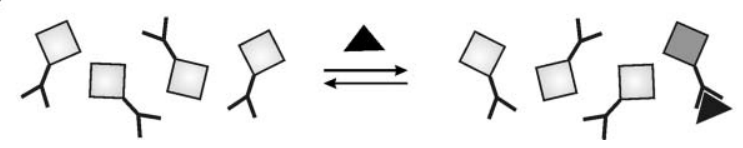

Fig. 8 (a) Conjugated polymer interacting with a small concentration of quencher giving complete quenching of the polymer chain. (b) Individual receptor-chromophore molecules exposed to a small concentration of quencher. This situation results only in a partial quenching. 
The use of water-soluble conjugated polymers for biosensors applications has been extensively studied by Bazan and coworkers. ${ }^{121-126}$ Fluorescent conjugated polymers as 2,2' -bipyridyl-phenylene-vinylene-based polymers, ${ }^{127}$ terpyridine-based poly ( $p$-phenylene-ethynylene)-alt-(thienylene-ethylene) polymers, ${ }^{128}$ poly( $p$-phenylene-ethynylene $)^{129}$ and others ${ }^{130}$ have been reported as sensitive probes for the detection of metal ions. ${ }^{131}$ "Turn-on" chemosensors based on CP have been developed for the sensing of metal ions by Jones and coworkers. ${ }^{132,133}$ There are only a few examples of anion sensing with conjugated polymers. The groups of Wang, ${ }^{134,135}$ Fujiki, ${ }^{136}$ and Swager $^{137}$ have reported the synthesis of fluorescent conjugated polymers able to detect fluoride anions, and the group of Schanze studied the sensing of other anionic quenchers. ${ }^{138}$ Sensing of neutral compounds have also been investigated. ${ }^{139,140}$ The most successful use of these semiconductor materials as fluorescent probes has been the design of sensors for the detection of vapors of nitroaromatic explosives such as trinitrotoluene (TNT) and dinitrotoluene (DNT) ${ }^{5,141}$ These semiconductive materials have been incorporated into sensors used for ultra-trace explosive detection in the search for hidden landmines. Devices with femtograms detection limits of TNT have been fabricated. ${ }^{142,143}$ In addition to fluorescent sensors, conductometric, potentiometric and colorimetric sensors based on CP have been studied. ${ }^{144}$

\subsection{Sol-gel materials}

Sol-gel materials encompass a wide number of inorganic and organic/inorganic composite materials which share a common preparation strategy. The sol-gel process is a method for the synthesis of ceramic and glass materials at low temperature. In a typical sol-gel process, a colloidal suspension, or a "sol" is formed via hydrolysis of alkoxy metal groups in the precursors and subsequent polycondensation. The result is a network with a glass-like structure which after the synthesis can be processed to a variety of shapes such as thin films, gels and ceramics. ${ }^{145}$ Based on the sol-gel process many different materials can be prepared and envisioned. Fluorescent dyes can be easily incorporated yielding doped glasses with powerful sensing applications. ${ }^{146}$ They have good optical properties, ${ }^{147}$ lack spectral interference (transparency and high refractive index), high mechanical and chemical stability, minimal quenching of fluorescence reagents and ease of fabrication. They can be fabricated at low temperatures and this allows the incorporation of organic molecules and polymers, leading to materials with added functionality which cannot be obtained otherwise. ${ }^{148}$ Additionally these materials are obtained from solution, which allows the convenient production of films and bulk materials of any possible shape. A major advantage of the sol-gel method is also that it produces porous materials whose pore-size distribution can be controlled by the chemical composition of the starting material and by the processing conditions. ${ }^{149}$ Another feature of sol-gels is their excellent adhesion to glass and other silica substrates due to the covalent linkage that is formed with the silanol groups of the glass surface. ${ }^{150,151}$

Organic molecules can be entrapped in a sol-gel matrix while still being accessible from solution. The main problem dealing with these materials is that the diffusion of the analyte to reach the recognition site is very slow. Leaching of the probes is also a big problem when continuous monitoring is needed. The first successful attempt to incorporate organic dyes and stabilize them within a sol-gel was reported in 1984 by Avnir et al. ${ }^{152}$

There are three methods to immobilize fluorophores or indicators in sol-gels: impregnation, which involves the chemical or physical adsorption on the glass surface, chemical doping incorporation of the dye during the formation of the sol-gel glasses, and covalent immobilization. ${ }^{145}$ Sensors made by physical entrapment can not be used after several weeks because a fraction of the dye molecule is usually leached. ${ }^{153,154}$ More stable sensors are prepared by covalent attachment of the dye to the polymer. ${ }^{155}$ Modification of silica gel with fluorescent probes for $\mathrm{pH}$ sensing was first reported by Soumillon and co-workers. ${ }^{156}$ They prepared a $\mathrm{pH}$ sensitive silica gel by the covalent attachment of an anthracene fluorophore to the surface of silica. Also pyrene for oxygen sensitivity, ${ }^{157}$ fluorescein isocyanate for fluorometric $\mathrm{pH}$ measurements, ${ }^{155}$ ruthenium complexes for oxygen ${ }^{158,159}$ or for $\mathrm{pH}$ sensing ${ }^{160}$ have been covalently attached to sol-gel glass films.

However, doping is actually the most common method for entrapment of the fluorophore in the glass. Some authors have suggested that covalent attachment might compromise the sensor performance by slower response times and smaller signal changes. ${ }^{161}$

Hydrophobic sol-gels based on precursors modified with organic groups, also referred to as ormosil glasses, show low penetration of water what make them appropriate for sensing of gases. Wolfbeis and co-workers reported the immobilization of ruthenium complexes on ormosils films and their use for $\mathrm{O}_{2}$ sensing. ${ }^{150}$

Using a different approach Rosenzweig and co-workers ${ }^{161}$ reported the immobilization of liposomes that encapsulate fluorescent dyes in a sol-gel film (Fig. 9). ${ }^{162}$ Liposomes, miniaturized containers for fluorescent sensing reagents are an alternative to covalent conjugation of the fluorescence molecules to phospholipid membranes or dextran chains.
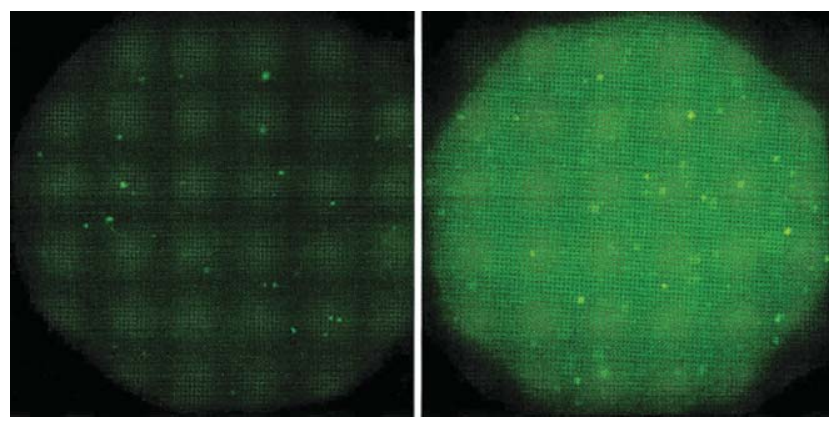

Fig. 9 Photographs of fluorescent liposomes immobilized in a sol-gel thin film: (left) a film containing a low density of liposomes. Individual liposomes can be seen indicating that the liposomes maintain their structural integrity when immobilized in the gel; (right) a photograph of a liposome containing sol-gel film of a typical liposome density used for the $\mathrm{pH}$ sensing measurements. (Reprinted with permission from ref. 162. Copyright 1999, Elsevier Science B.V.) 


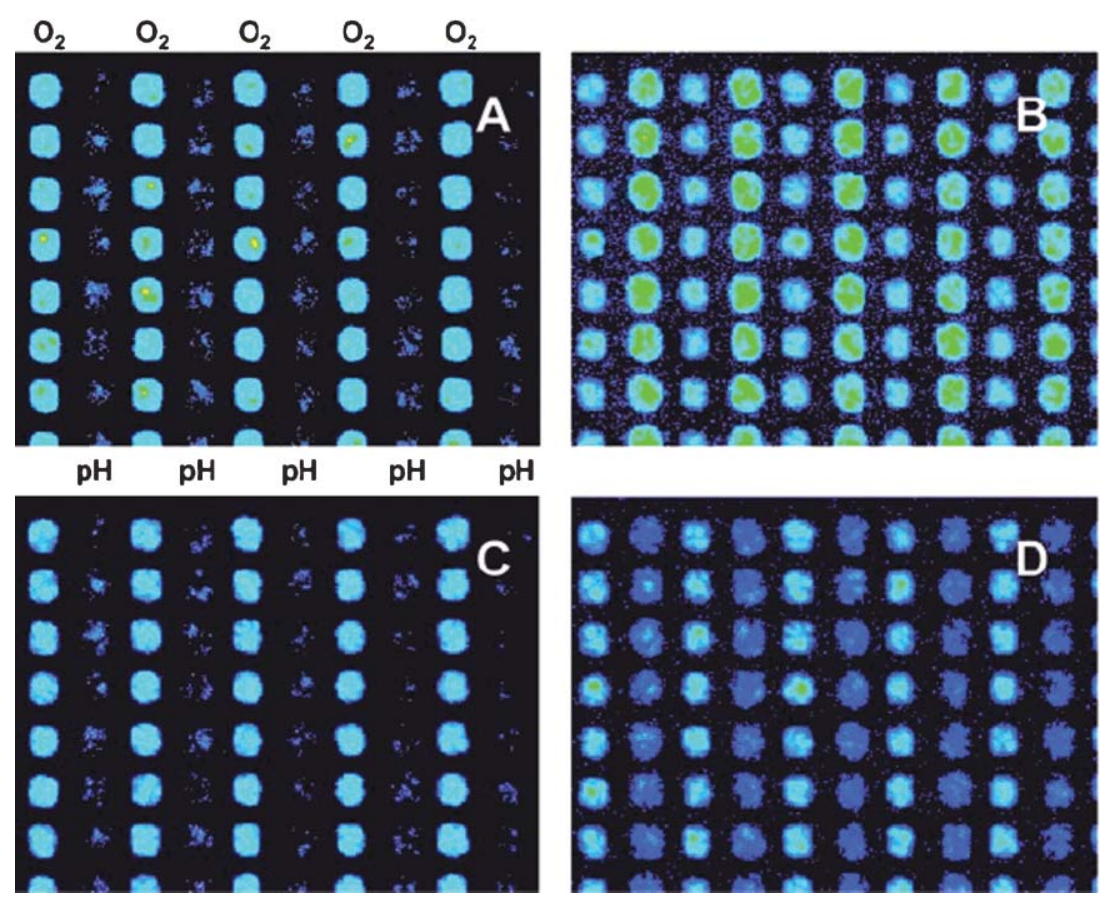

Fig. 10 False color CCD images from a typical dual-analyte, multianalyte pin-printed chemical sensor array. (A) $\mathrm{N}_{2}$-saturated water, $\mathrm{pH}$ 5.5. The columns of $\mathrm{O}_{2}$ - and $\mathrm{pH}$ responsive sensor elements are labeled. (B) Air-saturated water, $\mathrm{pH} \mathrm{8.0.} \mathrm{(C)} \mathrm{O}_{2}$-saturated water, $\mathrm{pH}$ 5.5. D) Air-saturated water, pH 4.0. (Reprinted with permission from ref. 166. Copyright 2002, American Chemical Society.)

The encapsulated fluorophores keep their solution properties, high emission, quantum yield and sensing capability. Carboxyfluorescein was used as $\mathrm{pH}$ sensing reagent because it is easily encapsulated in the liposome. Encapsulation of the fluorescent probe is an effective way to prevent dye leaking because it increases the size of the dye system and reduces the desorption of the dye from the matrix. ${ }^{163}$ In addition to the incorporation in a sol-gel material, individual loaded liposome have been used as nanosensors for intracellular $\mathrm{pH}$ and molecular oxygen sensing. ${ }^{164}$

In 2002 Cho and Bright combined sol-gel processing methods with pin printed technologies to fabricate a micrometer-scale xerogel sensor on a planar substrate. ${ }^{165}$ Sensor elements in the order of $100 \mu \mathrm{m}$ in diameter and $1-2 \mu \mathrm{m}$ thick at a rate of one sensor element per second and per pin can be made. Arrays of sensor elements for $\mathrm{O}_{2}$ and $\mathrm{pH}$ sensing based on xerogels doped with tris(4,7'-diphenyl-1,10'-phenanthroline)ruthenium(II) and fluorescein respectively, were fabricated (Fig. 10). ${ }^{166}$ High reproducibility was obtained for the detection of $\mathrm{O}_{2}$ and $\mathrm{pH}$ changes in aqueous samples. Afterwards the same concept was applied to create pin-printed biosensor arrays based on protein-doped xerogels. ${ }^{167}$

Another example of a $\mathrm{pH}$ sensor made by co-polymerized poly(vinyl alcohol) with tetramethoxysilane doped with fluorescein was reported by Werner and co-workers. ${ }^{168}$ Special attention was paid to the long-term stability and flexibility of the material.

Nocera et al. showed the integration of optical chemosensors and nanoscience by combination of a supramolecular chemosensor, thin film sol-gel, and microfluidics technologies. ${ }^{169}$ They fabricated a microfluidic device based on a fluorescent cyclodextrin modified with a $\mathrm{Tb}^{3+}$ macrocycle, which enhances its fluorescence emission upon interaction with biphenyl in aqueous solution. Thin films of the acryloyl polymer of the $\mathrm{Tb}^{3+}$-cyclodextrin complex were immobilized by sol-gel techniques on quartz surfaces patterned by photolithography methods (Fig. 11). The thin film showed the same sensing properties as the $\mathrm{Tb}^{3+}$-cyclodextrin complex in solution. Monitoring of the concentration from $5 \mu \mathrm{M}$ of biphenyl in aqueous solution was successfully performed. ${ }^{170,171}$

By varying the sol-gel processing conditions, molecularly imprinted sol-gel materials (MIP) with controlled porosity and surface area have been prepared. They have been used for separation, catalysis, receptors synthesis, selective adsorption, and preconcentration of the template molecules. ${ }^{172}$ While molecular imprinted sol-gels have been prepared for several applications, ${ }^{173}$ there are only few reports about fluorescent sensing with molecular imprinted sol-gels. In 2001 Lam and co-workers reported a fluorescent MIP material fabricated by conventional sol-gel processes which showed enhancement of fluorescence upon interaction with the analyte. ${ }^{174}$ The material made by the polymerization of $3-[N, N$-bis(9-anthrylmethyl) amino]propyltriethoxysilane, which acts as a photoinduced electron transfer (PET) monomer, was used for the detection of a non-fluorescent herbicide (2,4-dichlorophenoxyacetic acid) in water (Fig. 12). This new type of organic-inorganic hybrid MIP showed a significant affinity and selectivity for the analyte in aqueous media. However, the authors concluded that the sensitivity in neutral aqueous solution was not high compared with other MIP materials which are not based on PET.

A fluorescent molecular imprinted sol-gel for the fluorescent detection of 1,1-bis(4-chlorophenyl)-2,2,2-trichloroethane (DDT) in aqueous solutions was reported by Edmiston and co-workers, ${ }^{175}$ They used sacrificial spacer 


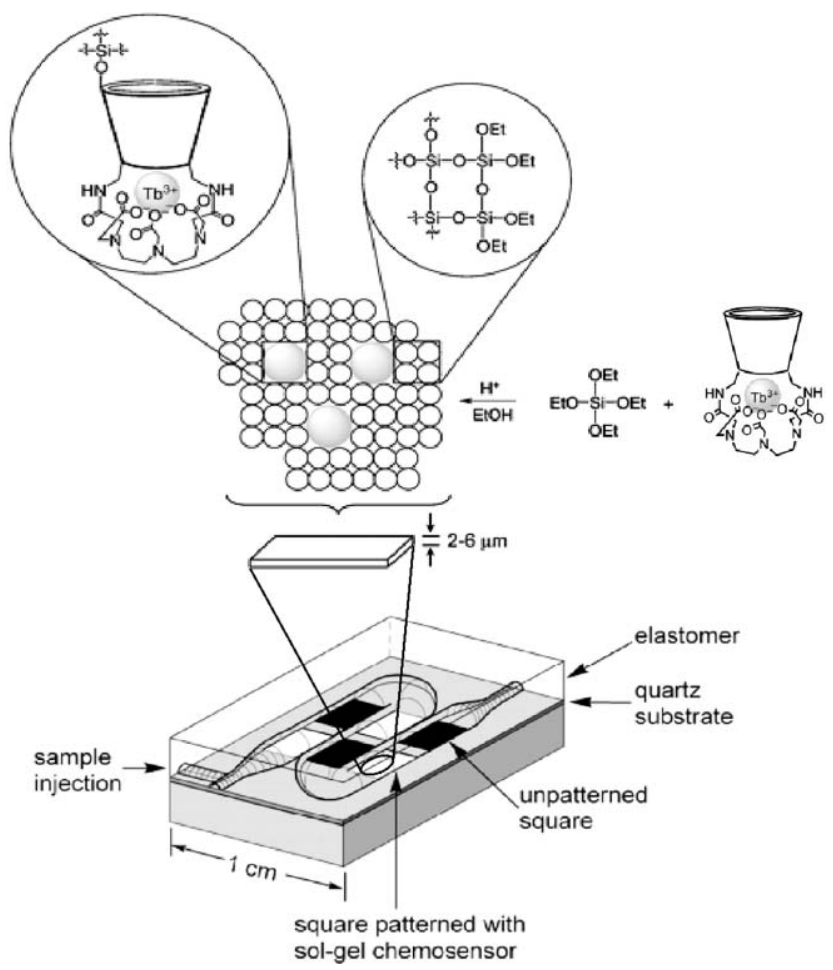

Fig. 11 Microfluidic optical chemosensor fabricated in a serpentine channel configuration. The white, sol-gel squares contain the supramolecular chemosensor, a cyclodextrin strapped by a DTPA macrocycle in which a $\mathrm{Tb}^{3+}$ ion resides. The conical bucket schematically represents the cyclodextrin receptor site. (Reprinted with permission from ref. 170. Copyright 2002, American Chemical Society.)

molecular imprinting. The template used to generate the binding site for the analyte on the polymer, is covalently linked to the polymer. Subsequently the template is cleaved off and the recognition pocket is formed. Additionally, a polarity sensitive fluorophore, 7-nitrobenz-2-oxa-1,3-diazol-4-yl (NBD), was incorporated close to the recognition site to signal the binding of the DDT within an imprinted binding pocket. The fluorescence intensity of the NBD dye increases in non-polar solvents, so displacement of water or other polar solvent close to the NBD by the analyte results in a fluorescence enhancement. The film produced in this way had a detection limit for DDT of $50 \mathrm{ppt}$ in aqueous solution. Even though the sensor showed good selectivity and sensitivity, it had few limitations such as minimal increases in fluorescence signal upon binding. Two explanations for this limitation were given by the authors. First the non-polar nature of the sol-gel material could force the NBD to be placed in a non-polar environment, therefore when a non-polar molecule was introduced in the recognition pocket, only a very small change in the environment of the NBD dye was induced. Second it could be that the NBD dye is not always close enough to the binding pocket in the matrix, therefore only a small amount of dye is able to transduce the binding event.

\subsection{Mesoporous materials}

In 1992 researchers of Mobil Company discovered MCM (Mobil Composition of Matter) a new class of silica-based materials. ${ }^{176} \mathrm{MCM}$ materials are ordered mesoporous materials which display a honeycomb-like structure of uniform mesoporous (3 $\mathrm{nm}$ diameter) running through a matrix of amorphous silica. They are the result of using surfactant/block copolymer as a template in sol-gel chemistry. Since the discovery of these materials various routes of functionalizing their inner surface have been reported to yield hybrid materials with improved adsorption, extraction, ion exchange, or catalytic abilities. ${ }^{177}$ Due to their high porosity (pore volume $1.0 \mathrm{~mL} \mathrm{~g}^{-1}$ ), concomitant large surface area (approximately $1000 \mathrm{~m}^{2} \mathrm{~g}^{-1}$ ) as well as their facile synthesis and robustness, MCMs are in principle ideally suited as a support material for

a)
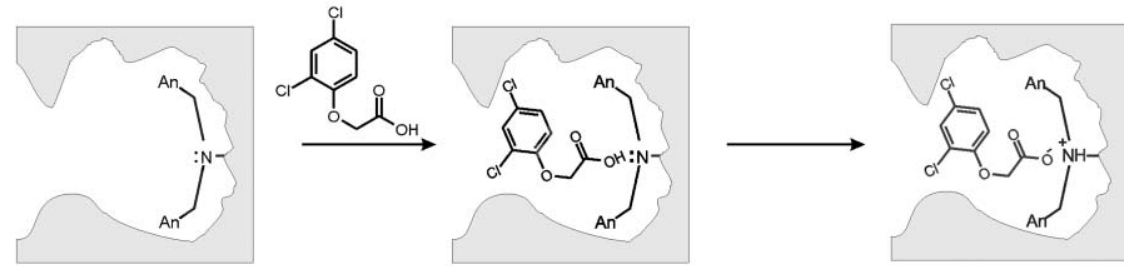

PET Quenching of anthryl fluorophores

PET Quenching suppressed, Fluorescence enhancement

b)

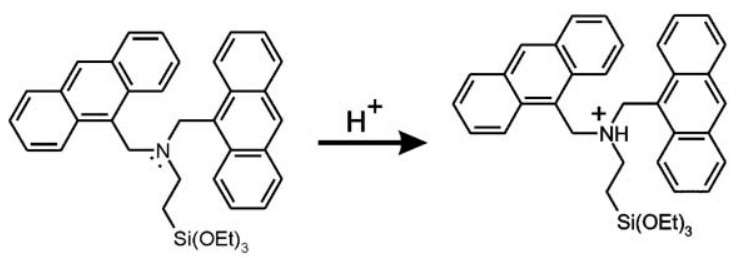

PET Quenching of anthryl fluorophores

PET Quenching suppressed, Fluorescence enhancement

Fig. 12 (a) Schematic representation of the interaction of 2,4-dichlorophenoxyacetic acid with the binding sites in the sol-gel derived MIP. PET processes lead to fluorescent responses. (b) PET process in the sensing anthrylmethyl monomer. (Adapted from ref. 174.) 
sensitive probes. Selective functionalization of the exterior and interior surface of structurally uniform mesoporous materials with different organic moieties allows precise regulation of the penetration of selective molecules with certain sizes and chemical properties into the nanoscale pores. The high surface area allows doping them with high concentrations of sensitive probes, and the highly uniform porosity allows for facile diffusion making them excellent hosts for sensing molecules or ions. ${ }^{178}$ Inner surface monofunctionalization or successive inclusion of different organic moieties can be achieved by cocondensation or post-synthetic covalent grafting of organic compounds $^{179}$ yielding higher-order hybrid materials that can be seen as a first step toward "biomimetic", "enzyme mimicking" or sensitive nanomaterials. ${ }^{180}$ From the point of view of engineering optical hybrid materials, microscopic mesoporous siliceous hosts possess the advantage of optical transparency in the visible to UV range, high dye dispersion, mechanical robustness, and high processability. ${ }^{181}$ The main differences with sol-gel glasses are the ordered sequence of surfactant and block copolymer/silica and holes (pores)/silica on the nanometer scale. Sol-gel synthesis of mesoporous silica with functional templates is very attractive for the fabrication of optoelectronic nanocomposite materials. ${ }^{180}$

Applications of these fluorescent mesoporous materials as optical sensing require stability against extraction or leaching of the dye molecules. Therefore dye molecules were covalently anchored to these materials. The goal was achieved in 1998 by co-condensation of fluorescently-modified triethoxysilyl anchor groups with tetraethoxysilane (TEOS). ${ }^{182}$ After this success numerous examples have been reported of covalent attachment of functional fluorescent dyes in mesoporous materials either by co-condensation with a fluorescent derivative or attaching the fluorescent dyes to nanosieve surfaces. ${ }^{183}$ The first examples of fluorescent mesoporous materials used for optical sensing were reported in $2001 .^{183}$ Mesoporous thin films covalently modified with fluorescein dyes showed a very fast response to $\mathrm{pH}$ variations. The response time of the thin films is in the order of $7 \mathrm{~s}$ for a $95 \%$ change in the emission intensity. The high porosity of the mesoporous thin film facilitates the fast diffusion of the solution towards the dye molecules. Brinker and co-workers fabricated a fluorescent $\mathrm{pH}$ sensor using a more elaborated approach involving patterning of surfaces with mesoporous materials. ${ }^{184}$ Mesostructures were formed by selective de-wetting of SAM modified substrates, followed by covalent modification of the mesoporous material with a fluorescent probe to form a microfluidic system for $\mathrm{pH}$ sensing (Fig. 13).

The use of hybrid materials, such as the fluorescently modified MCM solids, for anion-sensing systems was demonstrated in 2002 by Martínez-Máñez and co-workers. They showed that the combination of the binding properties of molecular receptors with the structure of the mesoporous materials results in a enhancement of the anion selectivity and sensing response in water. ${ }^{185}$ This micro-sized fluorescent probe was made by grafting aminoanthracene groups onto mesoporous silica materials. The amino groups bind ATP anions while the inorganic matrix provides the recognition pocket. Detection limits of $10^{-6} \mathrm{M}$ were obtained. The response of the grafted silica mesoporous material was better than that of silica membranes with the same functionalization and much better than the response of the aminoanthracene moiety free in solution. The solids exhibit cooperative effects that resulted in an improvement in ATP response with respect to the free probe in solution. This surface effect may arise from the cooperativity of the confined components of the system and the shape of the solid support itself (Fig. 14). ${ }^{186}$

Lin et al. synthesized a poly(lactic acid) (PLA) coated MCM type mesoporous silica nanosphere that served as a fluorescent probe for selective detection of amino-containing neurotransmitters under physiological conditions (Fig. 15). ${ }^{187,188}$ They utilized the PLA layer as a gatekeeper to regulate the penetration of molecules in and out of the nanopores monitoring the molecular recognition between the aminoneurotransmitters (dopamine, tyrosine, and glutamic acid) and a surface-anchored $o$-phthalic hemithioacetal (OPTA) group. The OPTA is a non-fluorescent moiety which reacts with these neurotransmitters that contain primary amines, forming a fluorescent isoindole derivative.

Optical sensing of different gas mixtures has been carried out with mesoporous molecular sieves that have covalently anchored rhodamine dyes. The concentration of $\mathrm{SO}_{2}$ in a gas can be deduced from the quenching of the fluorescence of the dye. ${ }^{189}$ Rurack and co-workers reported recently the synthesis of hybrid optical chemosensor materials for the detection of long-chain carboxylates. ${ }^{190}$ The mesoporous material was synthesized by the polymerization of 1-methyl-7-[N'(triethoxysilyl)propylureido]-3H-phenoxazin-3-one, which is the signaling moiety. a)

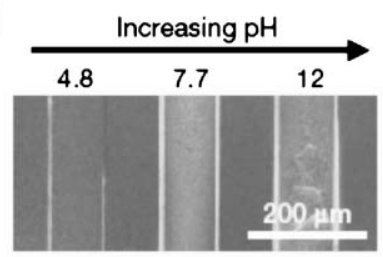

b)

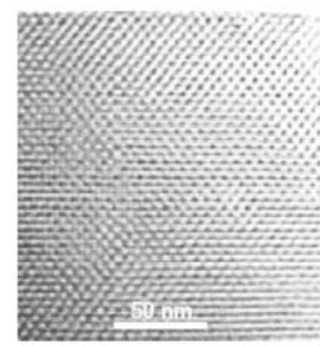

c)

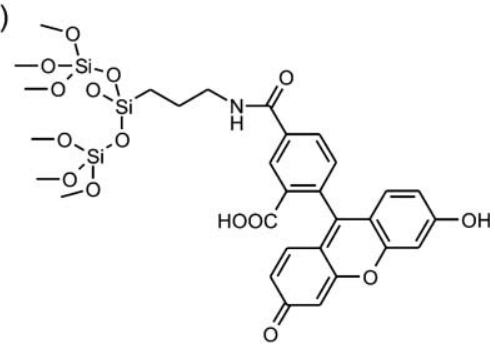

Fig. 13 (a) Fluorescence image of three adjacent pore channel networks for $\mathrm{pH}$ sensing, comprised by a thin film of mesoporous material modified with the fluorophore, carboxyfluorescein after introduction of aqueous solutions prepared at $\mathrm{pH} 4.8,7.7$ or 12.0. (b) Cross-sectional TEM micrograph of the patterned, dye-conjugated thin-film mesophase. (c) Schematic chemical structure of the carboxyfluorescein modified mesoporous material. (Reprinted with permission from ref. 184. Copyright 2000, Macmillan Publishers Ltd.) 
a)

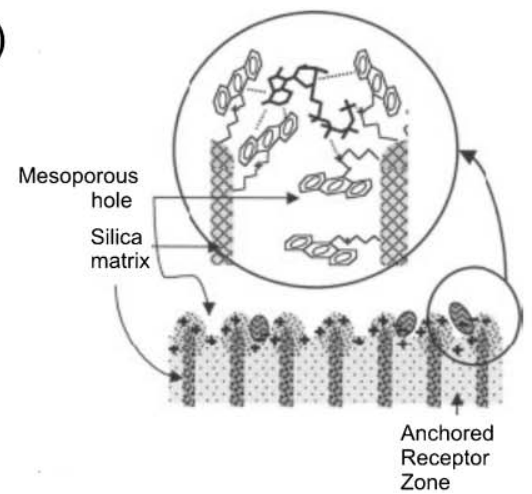

b)

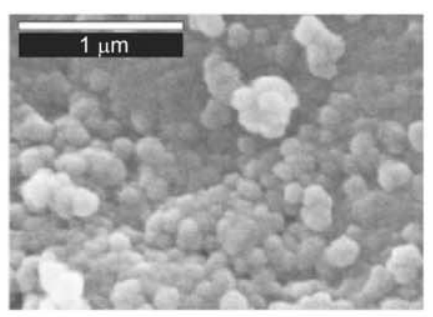

c)

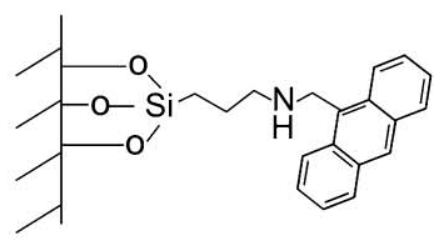

Fig. 14 (a) Schematic view of the surface of a mesoporous material modified with aminoanthracene and interacting with ATP anions. (b) SEM image of the modified mesoporous material. (c) Schematic representation of the chemical structure of the mesoporous material functionalized with amioanthracene. (Reprinted with permission from ref. 186. Copyright 2002, Wiley-VCH.)

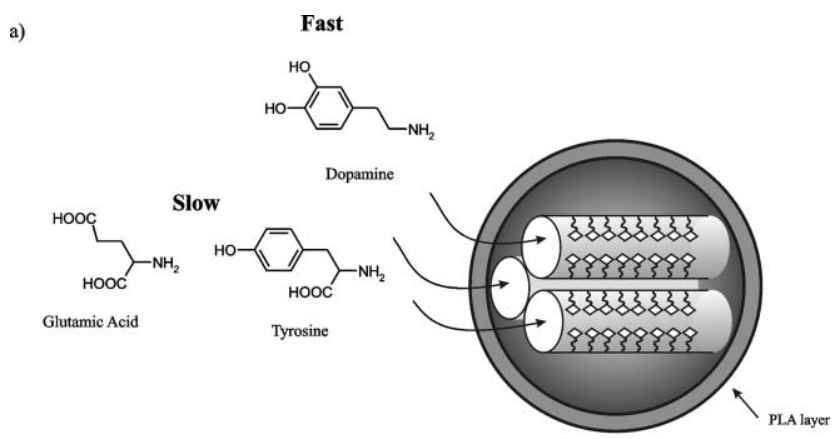

b)

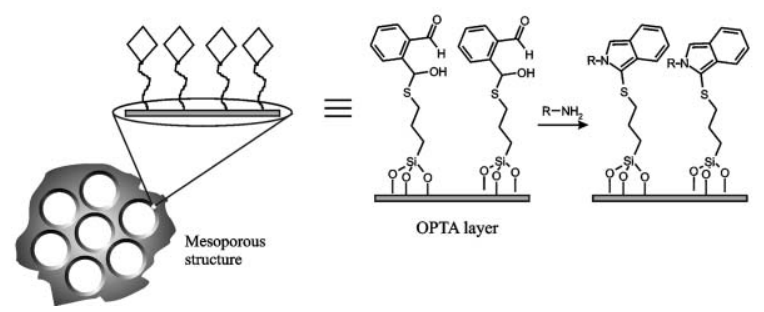

Fig. 15 (a) Schematic representation of the PLA-coated MCM based fluorescence sensor system for detection of amine-containing neurotransmitters. (b) Graphical and molecular representation of the functionalized internal walls of the nanopores. (Adapted from ref. 187.)

Specific ionophores such as calixarenes bearing two dansyl groups have been grafted on large porous silica materials via two long alkyl chains containing triethoxysilane groups to sense $\mathrm{Hg}^{2+}$ in water. ${ }^{191}$ The material responded reversibly to the presence of $\mathrm{Hg}^{2+}$ within few seconds and displayed a detection limit close to $10^{-7} \mathrm{M}$. Functionalized mesoporous solids can act also as binding pockets for anion-recognition in water using displacement colorimetric assays. ${ }^{192}$ Citrate and borate were selectively detected in water with a detection limit of $10^{-5} \mathrm{M}$ by this method.

\subsection{Surfactant aggregates}

In 1987 Wolfbeis and Schaffer published the first fluorescent chemical sensor built in a lipid bilayer. ${ }^{193}$ In this example the two parts of a fluorescent probe, fluorophore and receptor, are not covalently linked to each other. ${ }^{194}$ Langmuir-Blodgett films containing a lipophilic derivative of a potentiometric fluorophore (Rhodamine- $\mathrm{C}_{18}$-ester) and the $\mathrm{K}^{+}$selective ioncarrier valinomycin were prepared and used successfully for selective $\mathrm{K}^{+}$sensing.

In 2002 Leblanc and Andreopoulos demonstrated that the disconnection of receptor and fluorophore moiety of a fluorescent sensor could also be applied for lipid bilayer-based fluorescent sensors for $\mathrm{Cu}^{2+}{ }^{46}$ This system was based on lipophilic peptides as selective receptors for the metal ion and lipophilic dansyl derivatives. They compared the systems that have receptor and fluorophore covalently bound to the same lipid (5, Fig. 16) with the one with both moieties tailored to individual lipids (6 and 7, Fig. 16). In the first case an intramolecular interaction is responsible for the quenching of the fluorescence intensity of the dansyl fluorophore. In the second case, due to the proximity of both receptor and fluorophore after the self-assembly of the lipidic layer, the quenching is due to a through-space interaction. Additionally, the fluorescence quenching properties of the Langmuir monolayers were transferred to the one-layer LangmuirBlodgett (LB) films. The LB films showed sensitivity to $\mathrm{Cu}^{2+}$ even in presence of other metal ions with a detection limit of $10^{-5}-10^{-6} \mathrm{M}$.

Pallavicini and co-workers have shown recently that a hydrophobic fluorophore that self-assembled inside a micelle which contains receptor molecules can act as fluorescent sensing probe for metal ions in water. ${ }^{195,196}$ In this approach the receptor is covalently linked to a lipophilic tail which makes it insoluble in water. When the lipophilic receptor derivative is mixed with water containing a suitable amount of surfactant, micelles are formed. A pyrene fluorophore is encapsulated in the micelles by simple addition of the hydrophobic fluorophore to the aqueous micellar solution (Fig. 17). Binding of a metal cation to the receptor results in quenching of the fluorescence intensity by intramicellar electron-transfer (or energy transfer) processes. These micelles offer a certain degree of freedom since both receptor and fluorophores can be easily varied to create the system with the desired properties.

This work is similar to the work reported by Tonellato and co-workers in 1999 in which they exploited the self-assembly 

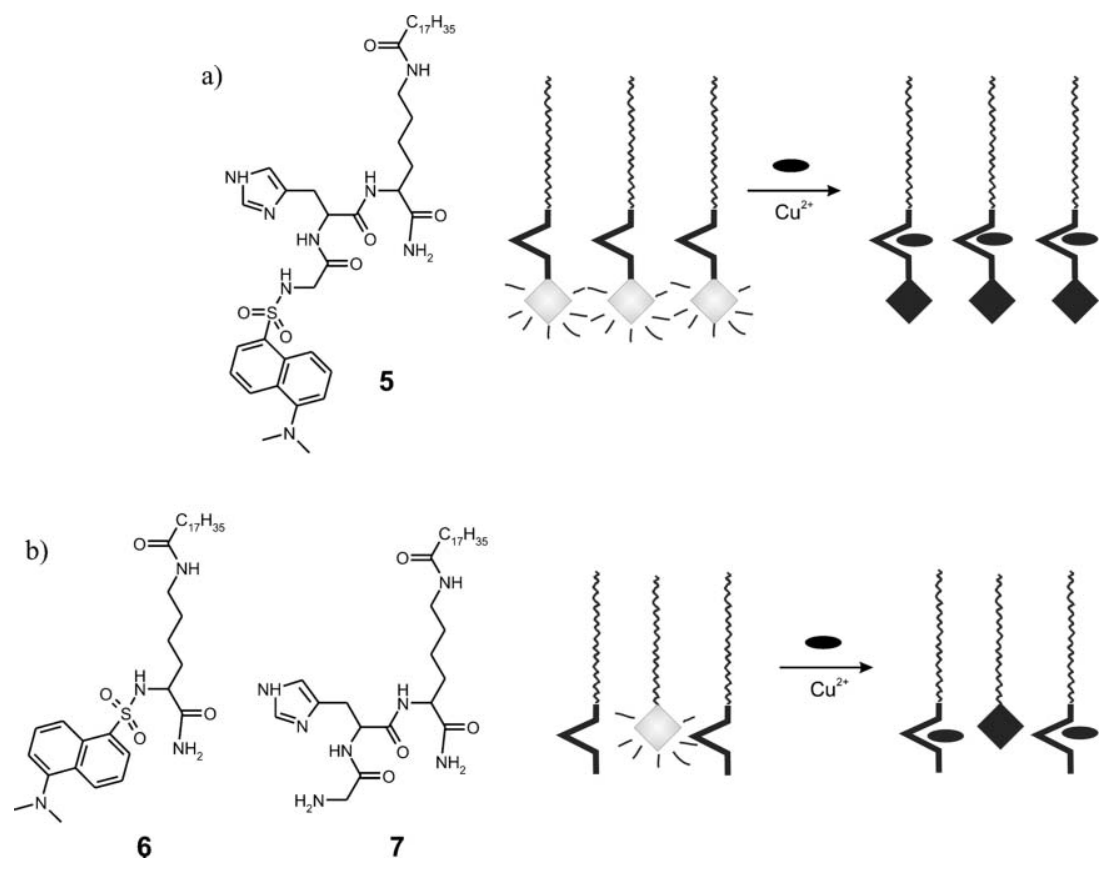

Fig. 16 Scheme of the proposed mechanism of the fluorescence quenching of the LB monolayers due to the interaction of the peptide derivate lipids with $\mathrm{Cu}^{2+}$ ions. (a) Scheme of the intramolecular sensing of $\mathrm{Cu}^{2+}$ with the monolayer of lipid 5. (b) Scheme of the intermolecular sensing of $\mathrm{Cu}^{2+}$ with the mixed monolayer of lipids 6 and 7. (Adapted from ref. 46.)

process to construct a $\mathrm{Cu}^{2+}$ sensor. They described the formation of comicellar aggregates by spontaneous assemble of a lipophilic $\mathrm{Cu}^{2+}$ ligand, a fluorophore and a surfactant. The fluorescence of the micellar aggregate was quenched upon formation of the $\mathrm{Cu}^{2+}$ complex with the lipophilic ligand. The system showed selectivity to $\mathrm{Cu}^{2+}$ in presence of $\mathrm{Zn}^{2+}, \mathrm{Ni}^{2+}$, and $\mathrm{Co}^{2+}$. The sensitivity depends strongly on the ratio surfactant-fluorophore used, reaching the micromolar range at low concentration of surfactant. ${ }^{194,197}$

Previously in 1995 Arnold and co-workers had reported a study in the metal-induced dispersion of lipid aggregates. They discovered that the binding of metal ions to metal chelating lipids in a membrane assembly induces dispersion of the lipids aggregates. For this study they used vesicles comprised by a pyrene-labeled lipid functionalized with iminodiacetic acid and distearoyl phosphatidylcholine. They measured the aggregation of the pyrene-labeled lipid using the monomer and excimer emission spectrum in the presence of divalent cations. The ratio of emission intensity of excimer and monomer was especially sensitive to the presence of $\mathrm{Cu}^{2+}$, reaching detection limits of $5 \mathrm{nM}$. They postulated that the sensitivity of the system could be modulated by the lipid concentration and the analyte-binding site affinity. ${ }^{198}$

Jelinek and co-workers reported the selective detection of catecholamines by artificial catecholamines receptors embedded in chromatic phospholipids/polydiacetylene (PDA) vesicles. ${ }^{47}$ Due to the conjugated (ene-yne) PDA backbone these vesicles show chromatic properties and fluorescence emission which can change upon surface perturbations (Fig. 18).

Only recently Pallivicini and co-workers have reported the first example of $\mathrm{pH}$ sensing using this micellar construction. They designed a smart system able to give a window-shaped
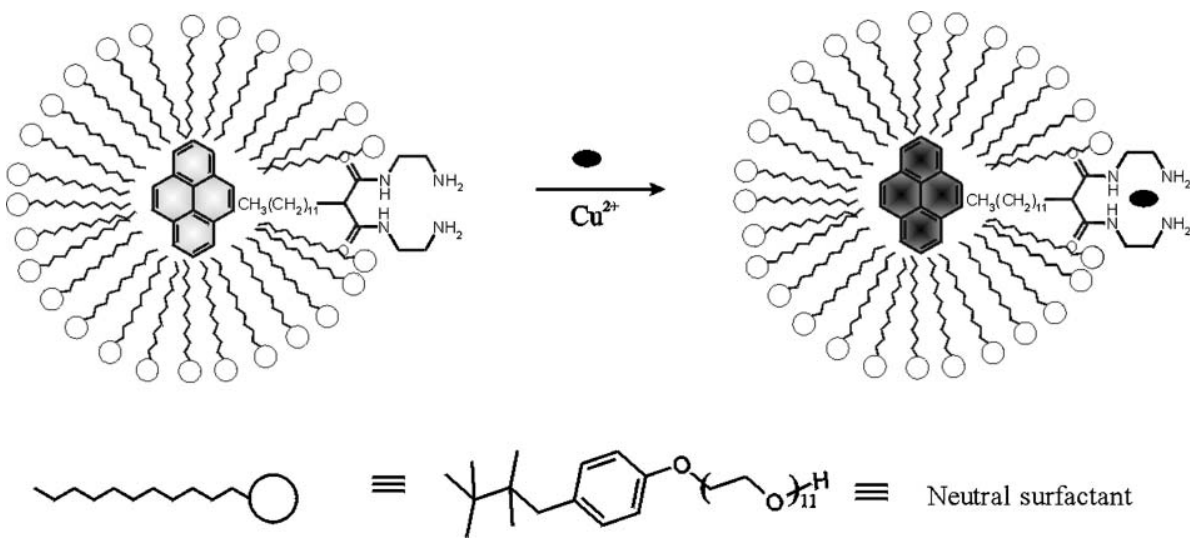

Fig. 17 Schematic representation of the sensitive micelle formed by mixing of a neutral surfactant, a selective receptor for divalent cations (dioxo2,3,2 lipophilized with a linear $\mathrm{C}_{12}$ chain) and pyrene. (Adapted from ref. 195.) 


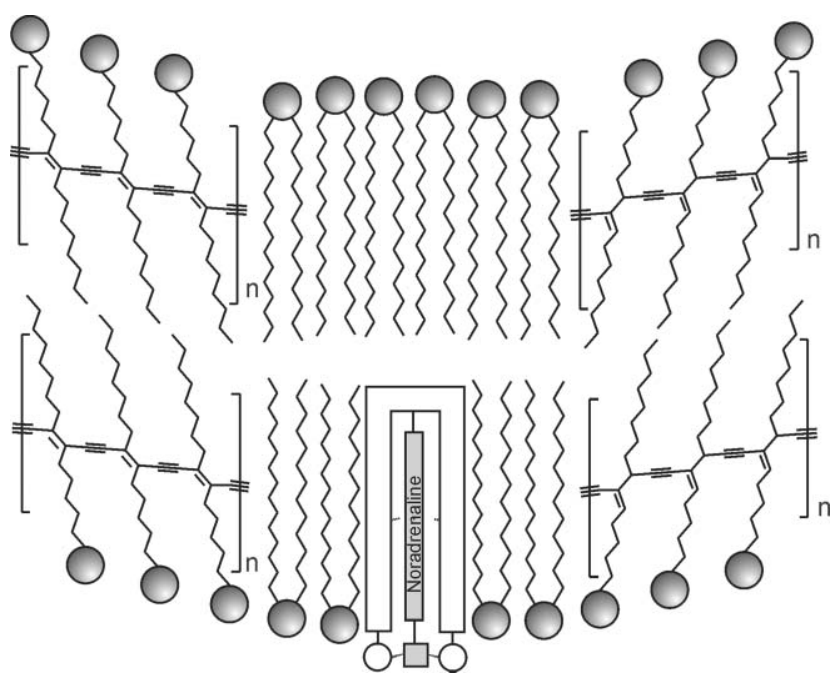

Fig. 18 Schematic description of the receptor/phospholipids PDA assembly (host in white, guest in grey). (Adapted from ref. 47.)

fluorescence intensity response vs. $\mathrm{pH}$, an off-on-off system. They used aggregates of pyrene with lipophilized pyridine and tertiary amine moieties. The off-on-off fluorescent states of the aggregates correspond to the $\mathrm{pH}$ value crossing the $\mathrm{p} K_{\mathrm{a}}$ value of the amine and the pyridine fragments, since protonated pyridines and free tertiary amines behave as quenchers. ${ }^{199}$

\subsection{Glass and gold surfaces}

Surface confined chemical sensing offers many advantages over physical entrapping methods of fluorophores in polymers or sol-gels; it avoids for example, leaking problems, offering long-term stability. Self-assembled monolayers (SAMs) adsorbed on gold surfaces or covalently bound to silicon oxide surfaces (glass, silicon or quartz) are suitable interfaces for sensing. ${ }^{200}$ They produce fast responses since all the receptors are exposed to the surface-liquid interface. Selfassembled monolayers are synthetically flexible so that they can be tailored to be chemically independent, they are cheap, durable and easy to immobilize on the transducer surface. ${ }^{201}$ SAMs can be easily and inexpensively manipulated to yield families of materials that provide independent chemical responses in the presence of target analytes. ${ }^{200}$ In spite of the fact that different functionalization of SAMs seems to be a convenient method for fabrication of fluorescent chemosensors the realization of such sensors is very scarce. SAMs on gold or other metallic surfaces have been extensively applied to chemo- and biosensing by electrochemical methods. The first examples of fluorescent sensing by SAMs used gold as substrate. However, SAM-based fluorescent sensors development has encountered difficulties due to an efficient fluorescent quenching by the metal surfaces. ${ }^{202,203}$ Only few reports have been published on the detection of fluorescence from selfassembled monolayers on gold. Motesharei and Myles reported in 1998 the preparation of layers of a fluorescent isophthalic acid adsorbate on gold. ${ }^{204}$ The binding of barbituric acid derivatives from acetonitrile was detected by a shift of the emission maximum up to $15 \mathrm{~nm}$. More recently

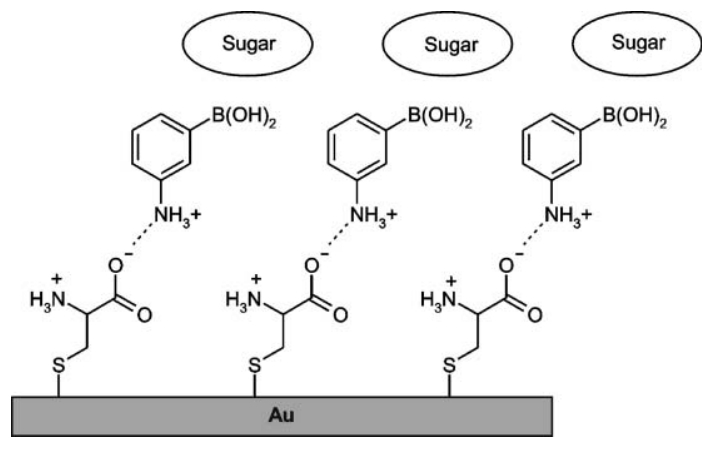

Fig. 19 Schematic representation of the self-assembled bilayer sensitive to the presence of sugars. (Adapted from ref. 205.)

Sun et al. have shown a monoboronic acid based selfassembled bilayer (SAB) fluorescent sensor for glucose and other saccharides with nanomolar sensitivity. ${ }^{205}$ They fabricated a stable fluorescent $\mathrm{SAB}$ on a gold surface using the amino acid cysteine and a fluorescent monoboronic acid. After the formation of the cysteine monolayer on the gold substrate, 3-aminophenylboronic acid (PBA) was assembled on the monolayer via electrostatic interaction with the cysteine (Fig. 19). They showed that the bilayer formation avoided the quenching of the fluorescence of PBA, which was enhanced upon interaction with glucose. ${ }^{203}$

Because glass does not display the problems of gold, i.e. it is transparent to light, it has been frequently used for fluorescent bioassays for biological studies (protein, DNA microchips, etc. ... $)^{206,207}$ and to prove energy transfer by assembly of donor and acceptor chromophores as mixed monolayers. ${ }^{208,209}$

The first effective sensing systems using covalently bonded dyes to glass were used for $\mathrm{pH}$ sensing. ${ }^{210,211}$ Almost 20 years ago Wolfbeis and co-workers ${ }^{212}$ reported the covalent immobilization of fluorescent acridinium and quinolinium indicators on a glass surface to create the first optical sensor for halides and pseudohalides. The sensors are able to indicate the concentration of halides in solution by virtue of the decrease in fluorescence intensity due to the quenching process. Another example of specific sensing probes covalently bound to glass surfaces was reported by Xavier et al. ${ }^{213}$ They developed a molecular oxygen sensor in non aqueous media by covalently attaching luminescent $\mathrm{Ru}(\mathrm{II})$ complexes via sulfonamide bonds to amino-derivatized porous glass (Fig. 20). In this very interesting work, the authors outline the influence of the immobilization procedure used for optical sensing in terms of sensitivity and stability. In contrast to physical techniques such as dissolution, adsorption and entrapment in a porous network, covalent immobilization of the luminescent indicator has been probed to increase the long-term stability of the sensitive system. Porous glass materials provide robust nonswelling rigid supports that can be easily modified with a number of chemical reactions. The resulting material displays strong emission above $600 \mathrm{~nm}$, which is effectively quenched by oxygen in both organic solvents and aqueous media, with a detection limit of $6.2 \mu \mathrm{M}$.

Recent developments in the chemistry of SAMs on glass have opened a new possibility for fluorescent chemosensor design. The parts of a fluorescent sensor can be covalently 


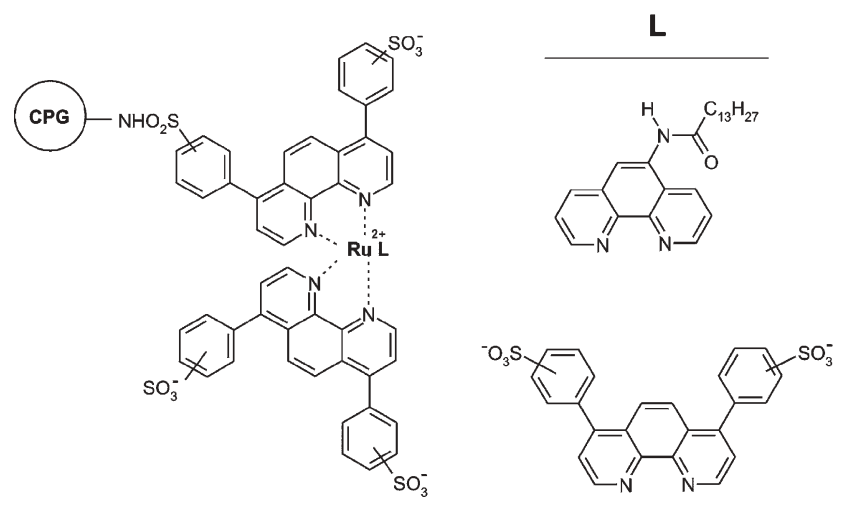

Fig. 20 Chemical structures of the controlled pore glass (CPG)immobilized Ru(II) complexes. (Adapted from ref. 213.)

attached to glass, silica and quartz in one or more synthetic steps relying on the ability of trialkoxysilanes or halogenosilanes to react with the hydroxylated surfaces of the substrates and to form self-assembled monolayers (SAMs). ${ }^{214}$ The first examples of fluorescent sensing on glass using self-assembled monolayers were reported by Reinhoudt and co-workers. ${ }^{215}$ They monitored the concentration of an aqueous $\beta$-cyclodextrin solution in the millimolar range using a dansyl modified amino-terminated SAM on glass. ${ }^{215}$ SAMs of dansyl adsorbates were prepared attaching a 3-aminopropyltriethoxysilane (APTES) monolayer to a glass plate and converting this layer into the desired dansyl SAM by reaction with dansyl chloride. The selective binding of $\beta$-cyclodextrin to the dansyl moieties produces an enhancement of the fluorescence intensity of the monolayer accompanied by a shift of the fluorescence maximum from 510 to $480 \mathrm{~nm}$ (Fig. 21).

Soon after another paper from this group reported the covalent attachment of a selective fluorescent calix-based receptor to a SAM for the detection of $\mathrm{Na}^{+}$in methanol down to $3.6 \mu \mathrm{M} .^{216}$ This was the first example of the detection of metal ions by fluorescence using a monolayer of a selective receptor. The novelty of this work was that it offered an alternative to physical immobilization of fluoroionophores in membranes. They probed that the fluoroionophore on the

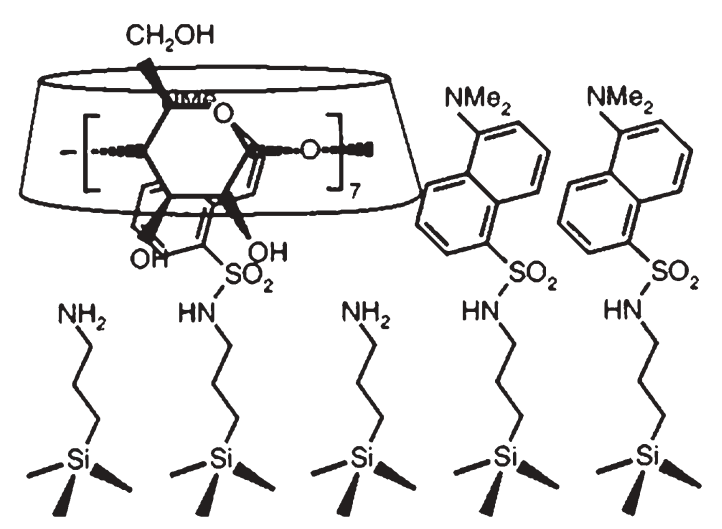

Fig. 21 Scheme for the selective binding of $\beta$-cyclodextrin to selfassembled dansyl monolayers on quartz surface, detected by fluorescence spectroscopy. (Reprinted with permission from ref. 215. Copyright 1999, Royal Society of Chemistry.) surface functions independently and that the confinement in the monolayer does not affect the complexation behavior. Similar work has been published recently by Wasielewski and co-workers ${ }^{217}$ They attached two identical fluorophores to the upper ring of a calix[4]arene, while the lower ring was functionalized to be attached either directly to a glass surface or to an amino terminated monolayer. Nevertheless, they have not reported the use of this fluorescent monolayer for sensing purposes.

The success of the approaches reported above relies on the synthesis and optimization of highly specific ionophores, which is a difficult and laborious task. Crego-Calama and Reinhoudt have developed a novel approach based on selfassembled monolayers on glass showing for the first time that disconnection between fluorophore and receptor can be applied to the preparation of stable sensitive fluorescent materials for metal ion sensing. ${ }^{44}$ They used SAMs on glass substrates as a 2D scaffold to impart sufficient molecular orientation to separately deposit various binding functionalities (rather than the entire receptor molecule) and the fluorophore on the surface to achieve analyte selectivity. By sequential deposition of a fluorescent probe and non-specific complexing functionalities, sensitive monolayers are produced. The randomly distributed fluorophores and functionalities generate a surface with a large number of sensing pockets (Fig. 22). The approach is a parallel combinatorial fabrication of sensing SAMs because different pairs fluorophore-complexing functionality yields surfaces with different complexing and sensing properties. The selectivity of these systems is not large but their performance is enhanced by the realization of cross reactive sensor arrays. ${ }^{218}$ This sensitive monolayers libraries have been used for the fluorescent sensing of inorganic anions in organic solvents, ${ }^{219}$ of metal ions in organic solvents ${ }^{44,219}$ and water, ${ }^{20}$ and for the fabrication of metal ion and luminescent patterns in glass surfaces. ${ }^{221}$ Using this approach they have also shown the fabrication of microfluidic devices for optical sensing of metal ions. ${ }^{219}$ Moreover, the sensing systems can be fabricated using microcontact printing, a soft lithography technique that permits to easily make controlledsize features down to $100 \mathrm{~nm} .^{219}$

Recently, the immobilization of a $\mathrm{pH}$ sensitive fluorophore (Oregon Green 514) inside of a glass microchannel, has yielded the first monolayer-functionalized microfluidic devices for optical sensing of $\mathrm{pH}$ (Fig. 23). ${ }^{222}$

Supramolecular interactions such as $\pi-\pi$ have been recently exploited to make sensitive glass surfaces. Cejas and Raymo have reported the functionalization of glass surfaces (quartz, glass slides and silica particles) with 2,7-diazapyrene derivatives for the detection of catecholamine neurotransmitters as dopamine (Fig. 24). ${ }^{223}$ The association of the 2,7-diazapyrenium acceptors with dopamine donors at the solid liquid interface produces a fluorescent quenching. The layers responded to sub-milimolar concentrations of dopamine and they showed selectivity for dopamine in presence ascorbic acid, which is the main interference in conventional dopamine detection protocols. Differently of what occurs in polymersbased sensors, the response time of SAMs is normally faster since all the recognition sites are directly exposed to the liquid interface. However, their sensitivity and dynamic range are 
a)
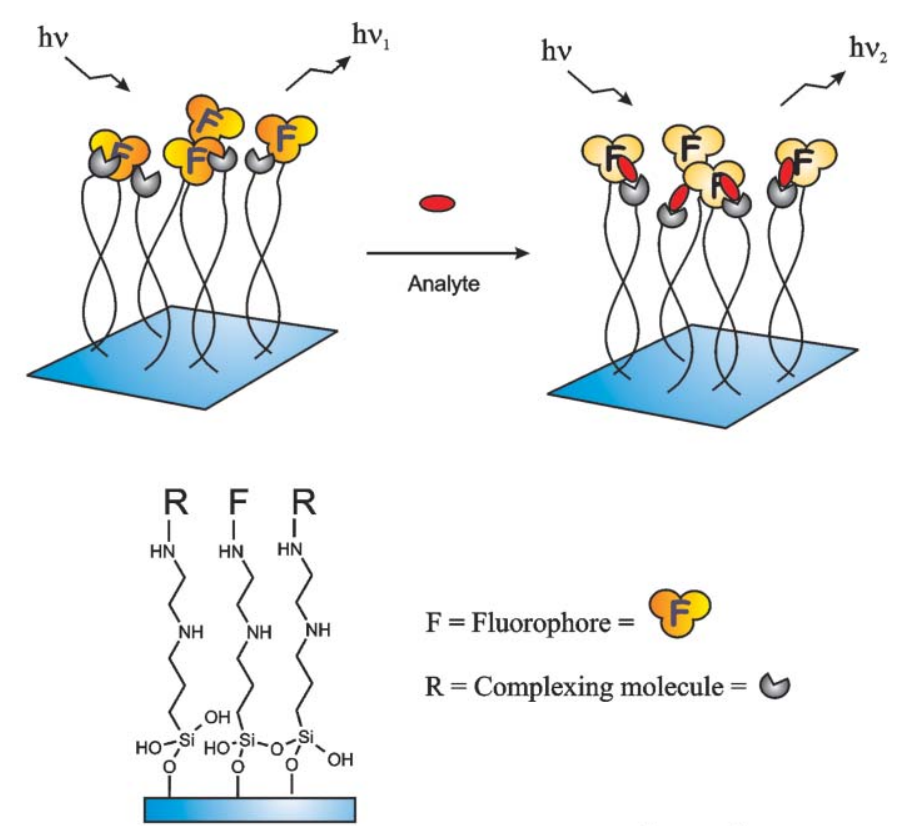

b)
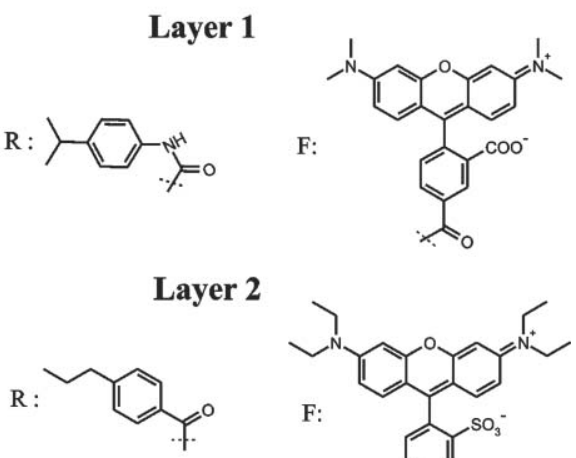<smiles></smiles>

Fig. 22 (a) Schematic representation of a self-assembled monolayer on glass with fluorophores and recognition sites independently attached. (b) Array of fluorescence confocal microscopy images of two different fluorescent SAMs (Layer 1 and Layer 2) in contact with acetonitrile (first spot) and $10^{-4} \mathrm{M}$ acetonitrile solutions of metal $\mathrm{Co}^{2+}, \mathrm{Cu}^{2+}, \mathrm{Ca}^{2+}$ and $\mathrm{Pb}^{2+}$ perchlorates. (Adapted from ref. 219.)

restricted by the limited number of receptors inherent to a planar surface. Probably in the future new strategies as functionalization of the monolayers with dendrimers to increase the number of recognition sites ${ }^{208}$ will be used.

\subsection{Nanoparticles}

There is a trend to miniaturize sensing materials, generally in the form of nanoparticles for the production of nanosize sensors. ${ }^{224-226}$ Miniaturization of sensors to nano-dimensions decreases their typical response time down to the millisecond time scale, exhibiting also spatial resolution at the nanometer scale. Due to their small dimensions, typically smaller than $100 \mathrm{~nm}$, nanosensing probes will find applications in intracellular analysis and in the fabrication of high density sensor arrays. ${ }^{29,84}$ The photostability of these miniaturized sensors is still a problem despite development of highly sensitive fluorescence detectors and the use of low light levels for excitation. ${ }^{225}$

Fluorescent sensing nanoparticles have been developed based on the attachment of a silanized receptor and silanized fluorophore on the surface of commercial silica colloids, ${ }^{77}$ the polymerization of a fluorescent derivative of a silanized receptor, ${ }^{227,228}$ the binding of selective receptors to dye doped polymeric $_{\text {particles }}{ }^{53}$ or to quantum dots. ${ }^{229}$

3.6.1 Silica and polymer-based nanoparticles. Since in 1996 Sasaki et al. demonstrated the employment of a single fluorescent nanoparticle as an optochemical sensor, ${ }^{230}$ many groups have devoted their efforts to the design and development of new nanosensors. Sasaki et al. reported a $\mathrm{pH}$-sensitive dye (fluorescein) entrapped in a polyacrylamine nanoparticle that was used to measure the $\mathrm{pH}$ distribution in the water glass interface. $^{230}$ Recently Montalti et al. synthesized silica nanoparticles bearing covalently linked luminescent chemosensors, and used them for the sensing of $\mathrm{Co}^{2+}, \mathrm{Cu}^{2+}$ and $\mathrm{Ni}^{2+}$ in the nanomolar range. ${ }^{227}$ The particles were synthesized by covalent attachment of a polyamine functionalized with a dansyl fluorophore to silica colloids. The result was the production of densely doped matrices. Due to the nanometric 

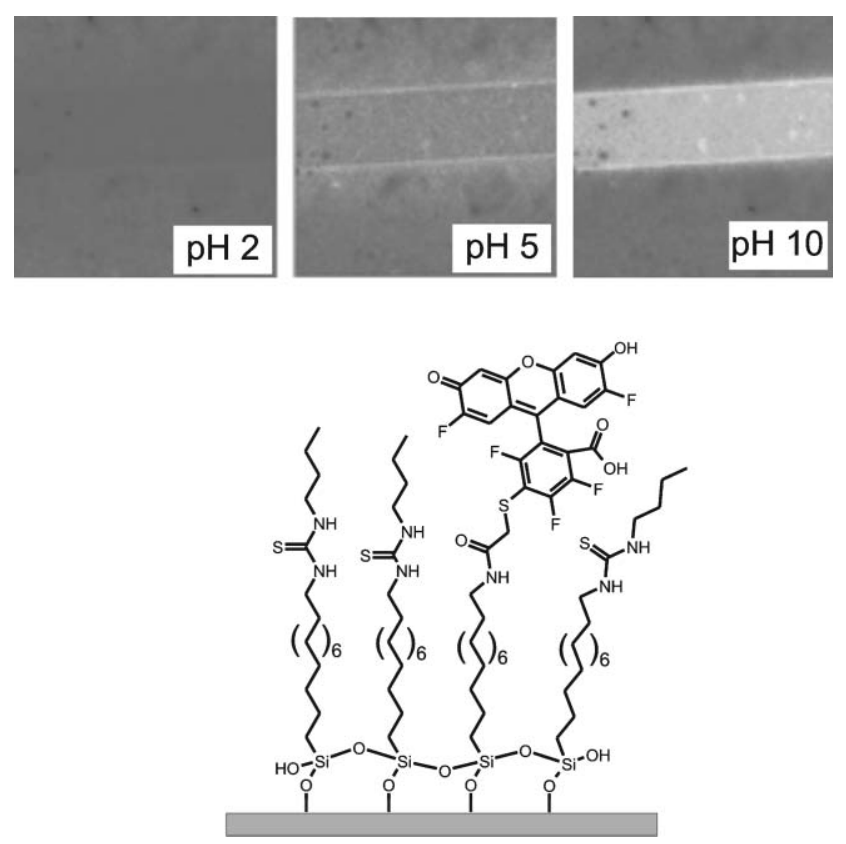

Fig. 23 Top: confocal microscopy images $(40 \times 40 \mu \mathrm{m})$ of a channel on the functionalized glass slide at three different $\mathrm{pH}$ values. Fluorescence emission intensity increases with the $\mathrm{pH}$. Bottom: representation of the composition of a fluorescent $\mathrm{pH}$ sensitive monolayer on glass. (Reprinted with permission from ref. 222. Copyright 2005, Royal Society of Chemistry.)

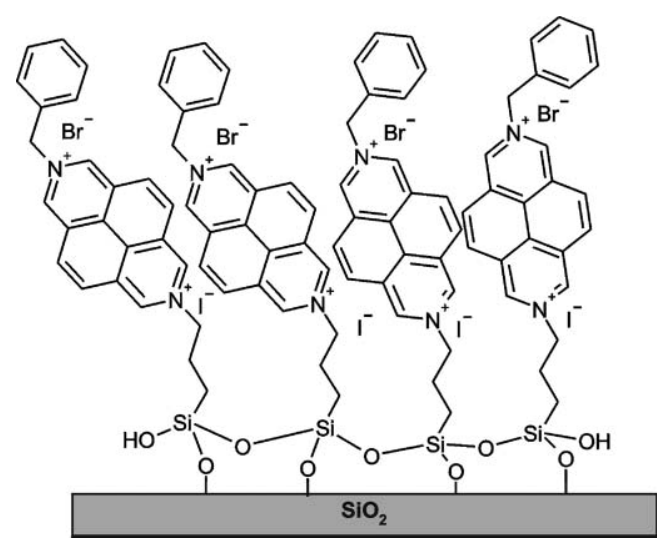

Fig. 24 Schematic structure of the dopamine sensitive 2,7-dizapyrenium monolayers on silicon substrates. (Adapted from ref. 223.)

dimensions of the particles and the high density of fluorophores, several photophysical processes can occur in this type of matrix leading to an important signal amplification, which is highly desirable in sensors to get low detection limits. ${ }^{95,228,231,232}$ The fluorescent quenching of the particles upon the presence of $\mathrm{Cu}^{2+}$ was estimated to be multiply by a factor of 13 (a single copper ion causes the quenching of 13 dansyl moieties).

Similarly Larpent and co-workers have reported the synthesis of nanometer-sized polymer nanoparticles (15$20 \mathrm{~nm}$ diameter) in which they associated a BODIPY derivative and a metal chelating receptor (cyclam). ${ }^{53}$ The hydrophobic dye is entrapped within the particle core and the receptor is covalently attached to the polymer backbone.

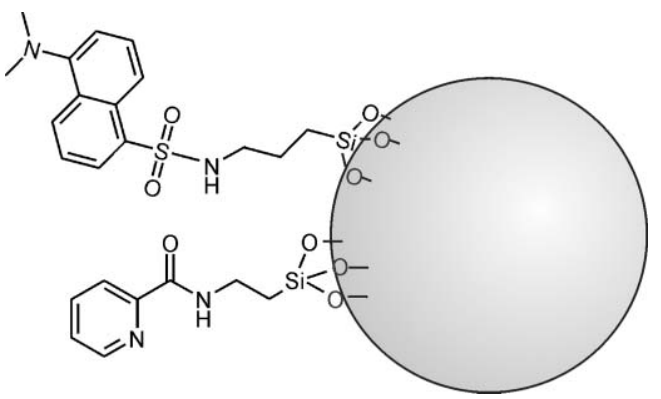

Fig. 25 Representation of the self-organized fluorescence chemosensor for $\mathrm{Cu}^{2+}$ ions obtained by surface functionalization of silica nanoparticles. (Adapted from ref. 233.)

The fluorescence intensity of the BODIPY is quenched upon $\mathrm{Cu}^{2+}$ binding to the cyclam ligand. Cooperation of the ligand subunits bound to the particle surface may form binding sites with an increased affinity for the substrate. ${ }^{233}$ They observed an important amplification of the quenching of the fluorophore upon binding of copper ions, presumably due to cooperative processes taking place in the nanoparticle. The particles could detect $\mathrm{Cu}^{2+}$ in the nanomolar range. They estimated that a single metal ion produced the quenching of 44 dye molecules. . $^{63,99,234}$

Tonellato and co-workers modified silica nanoparticles via the reaction of commercially available silica nanoparticles with average size of $18 \mathrm{~nm}$ with a trimethoxysilane derivatized dansylamide as reporter and a picolinamide as $\mathrm{Cu}^{2+}$ binding subunit. ${ }^{77}$ In this case receptor and fluorophores are not bound together but the spatial proximity is ensured by selfassembly of the sensing elements. The coated silica nanoparticles detected selectively $\mathrm{Cu}^{2+}$ down to micromolar concentrations in 9:1 DMSO-water solution. This approach is more versatile than the process of Montalti, since simple combinations of different silanes easily yield nanoparticles with different sensing properties ${ }^{43,233}$ without the need for additional synthesis of fluorescent probes (Fig. 25).

3.6.2 Quantum dots. In the early 1970s, low-dimensional heterostructures known as quantum dots (QDs) were developed. ${ }^{235}$ They are luminescent semiconductor nanocrystals of CdS or CdSe with exceptional chemical, electrical, and optical properties. Their importance was recognized by the 2000 Nobel Prize in Physics for Alferov and Kroemer. These luminescent particles, also called artificial atoms, have all three dimensions confined to the 1-10 nm length scale. As result of quantum confinement, they have unique optical and electronic properties such a broad excitation spectra and narrow, symmetric, and tunable emission spectra. The main advantage of the nanoparticles for the development of fluorescent sensors is that their luminescent emission depends on the size of the particle. Different sizes correspond to different color emission. ${ }^{236}$ Typically, their emission maximum is shifted to longer wavelengths with increasing particle diameter. These particles can be excited efficiently at any wavelength shorter than the emission peak yielding the same narrow and symmetric emission spectrum, characteristic of the quantum dot. Therefore, nanocrystals with many different sizes can be 
excited with a single wavelength of light resulting in many emission colors that may be detected simultaneously. ${ }^{237}$ In comparison with single organic fluorophores the QDs are brighter, more resistant to photobleaching and they have a wide range of emission colors. They can be capped with any organic material (a ligand) to modulate their complexing properties. ${ }^{238,239}$ They are very sensitive to surface interactions due to the unique discrete electronic state of each particle. Nevertheless, the mechanisms for the quenching or enhancement of luminescence are not yet clear. The discovery of these luminescent nanoparticles has opened the door to a new exciting approach to fluorescent chemical sensing. ${ }^{240}$ The use of luminescent quantum dots as probes for chemical and biochemical optical sensing has been recently reviewed by the Sanz-Mendel group. ${ }^{241}$ Nevertheless, important examples of QDs used for chemical sensing are commented below. In 1998 Bruchez et al. and Chan et al. reported simultaneously the first two QDs functionalized with biomolecules. ${ }^{237}$ The resulting nanoparticles were water-soluble and biocompatible and they were used as biological labels to recognize specific antibodies and antigens for use in ultrasensitive biological detection. ${ }^{242}$ Since then, QD-based approaches to fluorescent sensing have been used extensively for biosensing and labeling of biomolecules. $^{243-246}$

The application of QDs to fluorescent chemosensing of abiotic analytes was not demonstrated until 2002 by Chen and Rosenzweig. $^{229}$ They reported the analysis of $\mathrm{Cu}(\mathrm{II})$ and $\mathrm{Zn}$ (II) ions by CdS luminescent QDs capped with polyphosphate, L-cysteine, and triglycerol as selective probes in aqueous media.

Gattas-Asfura and Leblanc have synthesized a peptidecoated CdS QD for the detection of $\mathrm{Cu}(\mathrm{II})$ and $\mathrm{Ag}$ (I) selectively with sensitivity also in the micromolar range. ${ }^{45}$ Liang et al. have reported a new type of water-soluble CdSe quantum dot modified with mercaptoacetic acid for the quantitative and selective determination of $\operatorname{Ag}(\mathrm{I}){ }^{247}$ They obtained detection limits down to $10^{-8} \mathrm{M}$ and high selectivity for $\operatorname{Ag}(\mathrm{I})$ in presence of alkali and alkaline earth ions. Recently, a new method for $\mathrm{Cu}$ (II) sensing in water with a new type of functionalized CdTe nanocrystals has been shown. ${ }^{248}$ This system offers some extra advantages such as more stability against photobleaching and narrower emission peaks compared with CdS QDs. The narrow emission spectra allow closer spacing of different sensors without spectral overlap what might be applied for the development of multianalyte detection schemes.

Sanz-Mendel and co-workers made an important contribution to the used of QDs for the detection of anionic species. They first reported the determination of cyanide in organic media using tert-butyl- $N$-(2-mercaptoethyl)carbamate coated CdSe nanoparticles. They obtained a detection limit of $10^{-7} \mathrm{M}$ and good selectivity in the presence of other inorganic anions such as $\mathrm{NO}_{3}{ }^{-}, \mathrm{Cl}^{-}$or $\mathrm{SCN}^{-}{ }^{249}$ More interestingly, they have expanded this work to the determination of micromolar concentrations of cyanide in aqueous solutions using water-soluble QDs based on a 2-mercaptoethane sulfonate coating. Their method for cyanide detection is based on the measurement of analyte-induced quenching of the fluorescence emission of photoactivated nanoparticles. ${ }^{250}$
As we mentioned before, the efficiency of the QDs luminescence is sensitive to the presence and characteristics of adsorbates at the surface. Therefore, molecular recognition events at the surface of the nanoparticles could be easily monitored. Using a supramolecular recognition strategy, Kinjo and co-workers have presented the first use of QDs for the detection of neurotransmitters. They reported the detection of aceylcholine (Ach) at millimolar concentrations in aqueous solution with water-soluble CdSe/ZnS QDs, coated with amphiphilic $p$-sulfonatocalix[4]arene. The anionic calixarene binds the quaternary ammonium cation moiety of $\mathrm{ACh}$ in the hydrophobic cavity formed by the aromatic rings. ${ }^{251}$

Singaram and co-workers recently reported the use of fluorescent quantum dots to sense glucose in aqueous solution at millimolar concentrations. ${ }^{252}$ They showed a two component glucose-sensing system comprised by a boronic acid substituted viologen quencher and fluorescent CdSe/ZnS QDs. Modulation of the fluorescence signal occurs by competitive binding of glucose with the boronic acid receptor moiety (Fig. 26).

These semiconductor nanoparticles can be unstable and tend to coalesce into bigger particles due to their high surface energy. Organic coatings such as thiol molecules or $\mathrm{SiO}_{2}$ coatings can be used as stabilizing agents; these coatings can be unfavorable when using the nanoparticles for sensing purposes since they can act as a barrier for the diffusion of the analyte to the surface of the nanoparticle. Nevertheless size-selective molecular detection systems can be envisioned making used of the porosity of the coating. Torimoto et al. have reported the preparation of photoetched $\mathrm{CdS}$ cores coated with $\mathrm{SiO}_{2}$ using a size-selective photoetching technique $e^{253}$ and the study of their photoluminescent quenching in the presence of several types of trialkylamines. ${ }^{254}$

Recently Scaiano and co-workers reported a very interesting study on the doping of photonic crystal fibers with $\mathrm{CdSe}$ quantum dots. ${ }^{255}$ The combination of the fluorescent
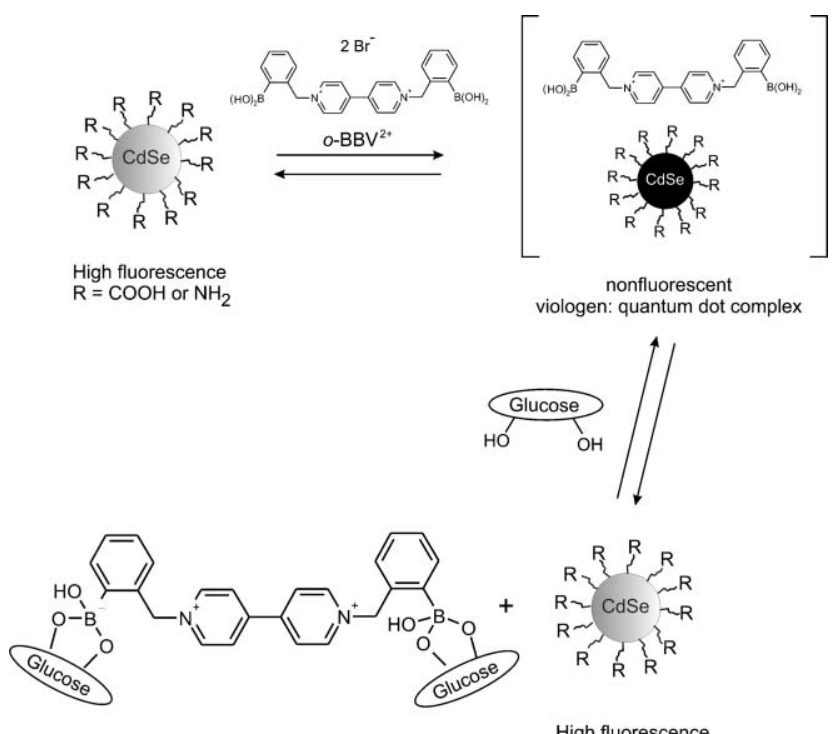

Fig. 26 Schematic of the mechanism for glucose sensing with fluorescent QDs. (Reprinted with permission from ref. 252. Copyright 2006, Wiley-VCH.) 
properties of QD and the unique light transmission properties of photonic crystal fibers is extremely exciting for the development of new chemosensory devices.

Konoshi and Hiratani have reported a new type of "turnon" sensor for $\mathrm{Cu}^{2+}$ at nanomolar concentrations in water solutions based on CdS cluster molecules. The water-soluble $\mathrm{CdS}$ cluster molecules were capped with oligo(ethylene glycol), and showed a large enhancement of fluorescent emission in the presence of $\mathrm{Cu}^{+}$and $\mathrm{Cu}^{2+}$ with high selectivity for copper in the presence of many other metal ions. ${ }^{256}$

\subsection{Nanosensors}

The field of fluorescent nanosensors has taken advantage of the recent progress in fluorescence imaging instrumentation that makes it possible to detect single fluorescent molecules and therefore to measure the signal changes of fluorescent nanosensors. ${ }^{29,257}$

In 1998, Kopelman and co-workers prepared a new type of nanosensor denoted PEBBLEs ${ }^{258}$ (probes encapsulated by biologically localized embedding). The PEBBLEs are watersoluble polymer nanoparticles (cross-linked polymers as polyacrylamide, poly-decylmethacrylate, sol-gel silica, etc.) with sizes raging from $30 \mathrm{~nm}$ (1 ppm of a normal cell's volume) to $600 \mathrm{~nm}$ in which fluorescent analyte-sensitive indicator dyes and analyte-insensitive reference dyes are entrapped in order to perform ratiometric measurements. Their small size and their chemically inert matrices enable intracellular non-invasive analysis with fast response and high spatial resolution. These nanoparticles have been used to fabricate $\mathrm{H}^{+}, \mathrm{O}_{2}, \mathrm{Ca}^{2+}, \mathrm{K}^{+}$, $\mathrm{Zn}^{2+}, \mathrm{Cl}^{-}, \mathrm{NO}_{2}{ }^{-}, \mathrm{O}_{2}, \mathrm{NO}$, and glucose sensors. ${ }^{75}$ They show very high selectivity, fast response and reversibility. They can be used to obtain information of multiple cells at the same time. Different systems can be created by combining multiple dyes and ionophores inside the polymeric matrix. ${ }^{259}$ For example, Kopelman and co-workers have reported a ratiometric sensor for intracellular oxygen which was made by the inclusion of a ruthenium complex (Ru(II) tris(4,7-diphenyl1,10-phenanthroline) chloride) and Oregon Green in a polymer nanosphere. ${ }^{260}$ The fluorescence emission of the ruthenium complex is quenched strongly in the presence of oxygen while the fluorescence of the Oregon Green is not affected, thus allowing ratiometric intensity measurements of the oxygen concentration (Fig. 27).

A PEBBLE nanosensor for intracellular iron(III) sensing has been recently reported. ${ }^{261}$ These PEBBLEs have the fluorophore Alexa Fluor 488 as a recognition element and the fluorophore Texas Red as a reference dye in a polyacrylamide matrix. These optical nanosensors have two main benefits: protection of the sensing component from interfering species within the intracellular environment and protection of the intracellular environment from toxic effects on the sensing component.

Rosenzweig and co-workers have used liposomes as fluorescent nanosensors ${ }^{48}$ for intracellular measurements of $\mathrm{pH},{ }^{164} \mathrm{Ca}^{2+},{ }^{262}$ and $\mathrm{O}_{2} .{ }^{263}$ The sensing reagents are encapsulated in the internal aqueous area of the liposomes and they retain their free solution properties. Current research focuses on multi-analyte detection. There is also a large development

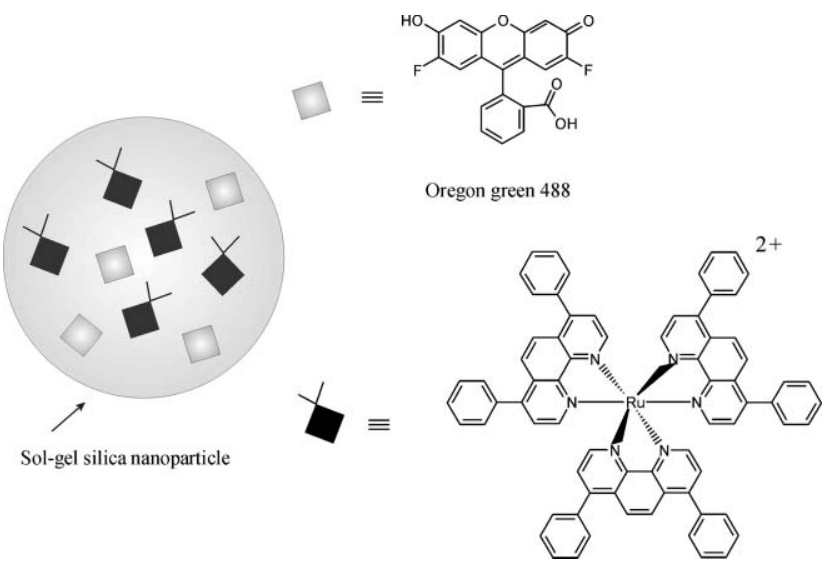

Fig. 27 Example of a ratiometric PEBBLE using Ru-DPP sensing dye and Oregon green dye entrapped in a sol-gel silica particle of $20 \mathrm{~nm}$. a)

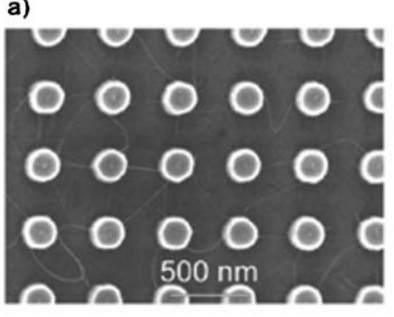

b)

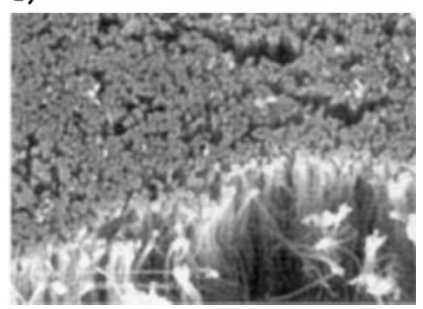

Fig. 28 (a) Scanning electron micrograph of suspended nanotubes on pillars. Reprinted with permission from ref. 268. Copyright 2004, Springer-Verlag. (b) SEM images of a carbon nanotube tube array. (Reprinted with permission from ref. 308. Copyright 2003, Wiley-VCH.)

in the modification of the surfaces of these particles with bioactive molecules for biosensors. ${ }^{264}$

Novel nanostructures such as one-dimensional single-wall carbon nanotubes (SWNTs) appear highly promising substrates for the development of optical sensors and sensor arrays. They show electrical conductivity comparable to that of conjugated polymers (see above) and are sensitive to substances that affect the amount of injected charge. ${ }^{265,266}$ Additionally they have very good mechanical and thermal properties, and can be tailored with chemically and biologically responsive ligands. ${ }^{267}$ Homma and co-workers reported photoluminescence from individual SWNTs ${ }^{268}$ situated in the near-infrared (Fig. 28). Quenching of the fluorescence by $\mathrm{O}_{2}$ absorption was reported by Strano et al. ${ }^{269}$ and $\mathrm{pH}$-dependent bleaching has also been observed. ${ }^{270,271}$

\section{Combinatorial methods for sensing and sensor arrays}

Our ability to predict the structural requirements for a perfect fluorescent probe for each analyte is limited and the trial and error approach is still widely used for chemical sensor design. ${ }^{20}$ Therefore, combinatorial approaches to the discovery of both, binding and fluorescence building blocks would be powerful if effective library schemes could be invented. The combinatorial concept is based on the relative ease of production of a large 
number of potential compounds or devices. It is clearly different from the "classical" rational design and individual production of specific targets. ${ }^{272}$ It allows the production of a large number of targets, which can be tested to determine successful hits. Linked to a proper screening methodology and data processing, it allows for facile search and optimization of a target lead structure, e.g. drug discovery, catalysis, bimolecular interaction studies or sensitive probe discovery. ${ }^{273}$ Many different types of combinatorial methods have been already employed to obtain new sensitive optical probes. ${ }^{110,273-282}$ Solid-phase organic synthesis is a well-established tool for the production of combinatorial libraries, but it has been mainly used for drug discovery. Resin bound chemosensors for several analytes have been made by combinatorial methods. Anslyn reported how the split and pool method was used to generate a combinatorial library of more than 4000 different resin bound tripeptides for the discovery of ATP binding receptors. After discovery of the ATP binding receptor, fluorophores were appended to the end of the peptide chains in order to produce a sensing probe (Fig. 29). ${ }^{276}$

Castillo and Rivero has reported the use of alkylphosphine sulfides bound resins for $\mathrm{Pb}^{2+}$ and $\mathrm{Cu}^{2+}$ sensing. ${ }^{283}$ Combinatorial chemistry has also been used to improve selectivity in some molecular imprinted polymers. ${ }^{102}$ Parallel peptide synthesis was used for a cyclopeptide library attached to a glass surface that works as an amino acid sensor by reflectometric interference spectroscopy. ${ }^{284}$ Libraries of fluorescent polymers have been also generated by combinatorial methods by the group of Dordick. ${ }^{274}$ They developed a sensor array for divalent and trivalent metal ions consisting of fifteen phenolic homopolymers and copolymers generated from five phenolic monomers. The sensing process is based on the change of the intrinsic polyphenol fluorescence upon addition of a metal ion mixture to an aqueous suspension of the polyphenol.

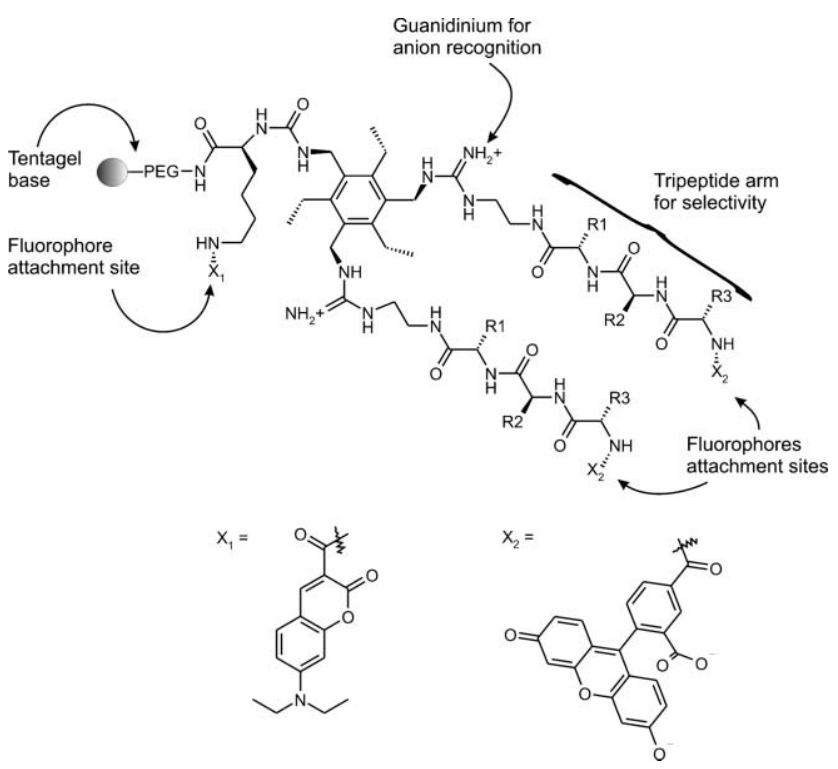

Fig. 29 Example of some probes for ATP sensing based on resin bound tripeptides generated by combinatorial methods. (Reprinted with permission from ref. 276. Copyright 2000, American Chemical Society.)
The vast number of targets produced by combinatorial methods creates the need for effective and efficient screening for the hit identification. To this end, surface immobilization and individual addressability of chemical sensing systems are advantageous because they allow for facile analyte sensing to be performed in parallel. ${ }^{273,285}$ For that purpose platforms, originally exploited in the field of biosensors, have been developed that facilitate high-throughput screening (HTS) technologies, such as microtiter plate or microarray technologies, fiber optic tips, and solid-phase synthesis. ${ }^{286}$ For instance, Gauglitz and co-workers have performed a label-free parallel screening of a combinatorial triazine library solidphase synthesis at the bottom of a microtiterplate by reflectometric interference spectroscopy (RIfS) (Fig. 30). ${ }^{287}$

Wolfbeis and co-workers reported a combinatorial approach for the optimization of hydrogel materials for use in fluorescent sensing of alkali-metal ions by depositing the sensor layers at the bottom of the microtiter plate wells. ${ }^{288,289}$ Crego-Calama and Reinhoudt have introduced a parallel library generation of fluorescent self-assembled monolayers on glass for ion sensing. ${ }^{44}$ Combinatorial methods have been also successfully used to generate arrays of nonspecific sensors

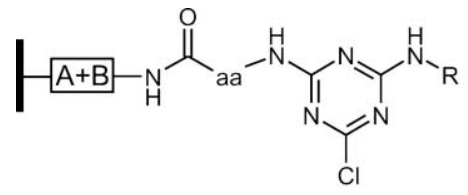

$A=$ Silane $; B=P E G$ (spacer)

$\mathrm{R}=$ Different amino residues

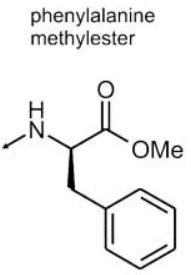

adamantylmethylamine<smiles>CNCC12CC3CC(CC(C3)C1)C2</smiles><smiles>CNCCc1c[nH]c2ccccc12</smiles>

pentylamine<smiles>CCNC</smiles><smiles>[CH]1CCCC1</smiles><smiles>C1CCCCNCCC1</smiles>

2-aminopyrimidine<smiles>CNc1ncccn1</smiles>
trimethoxybenzylamine<smiles>CNCc1c(OC)cc(OC)cc1OC</smiles><smiles>CNC(C)C</smiles><smiles>CNCCc1ccccn1</smiles><smiles>CNc1ccc(C)cc1</smiles>

Fig. 30 Triazines library generated by combinatorial methods in the wells of a micotiter plate. (The thick black line on the left represents the glass bottom of the well). (Reprinted with permission from ref. 287. Copyright 2002, American Chemical Society.) 
comprised of partially specific molecular receptors. ${ }^{272,290}$ This new approach is inspired by the mammalian olfactory system in which a limited number of not very selective cross-reactive receptors is able to generate a response pattern. ${ }^{87,291-293}$ These cross-reactive sensor arrays (artificial noses ${ }^{294}$ and tongues ${ }^{295}$ ) are created such that specificity is distributed across the array's entire reactivity pattern rather than contained in a single recognition element. Such patterns can be then incorporated in an artificial neural network for recognition of mixtures of analytes. $^{296,297}$ The first artificial nose was fabricated by Persaud and Dodd based on an array of cross-reactive conjugated polymer sensors. ${ }^{298}$ Since then the field of artificial olfaction and gas determination is one of the fastest growing areas in sensing. ${ }^{299,300}$ Artificial tongues have been developed for the analysis of liquids. ${ }^{87,293}$ The first artificial nose based on organic dyes was reported by Walt and co-workers in $1996 .^{301}$ It relies on polymer-immobilized dye molecules on optical fiber tips. On exposure to organic vapors different fluorescent response patterns are generated. One year later they reported an improved methodology, which relied in the use of combinatorial methods to generate a library of different polymers. ${ }^{59}$ A larger number of elements in a sensor array facilitate the recognition of an analyte or mixture of analytes. The high-density arrays are commonly made by incorporation of micro-sized polymeric beads stained with fluorescent dyes and in the latter case with chemical ionophores in micrometersized wells (which can actually go down in size to $250 \mathrm{~nm}^{302}$ ) etched in the fiber core tips (Fig. 31). Fiber optic bundles have a miniature feature size (up to 10 -micrometer diameter) allowing high-density sensor packing $\left(2 \times 10^{7}\right.$ sensors per $\left.\mathrm{cm}^{2}\right) .{ }^{303}$ They transmit coherent images enabling combined imaging and sensing, relating the responses monitored by the sensor to observable physical changes. The Walt and Bakker

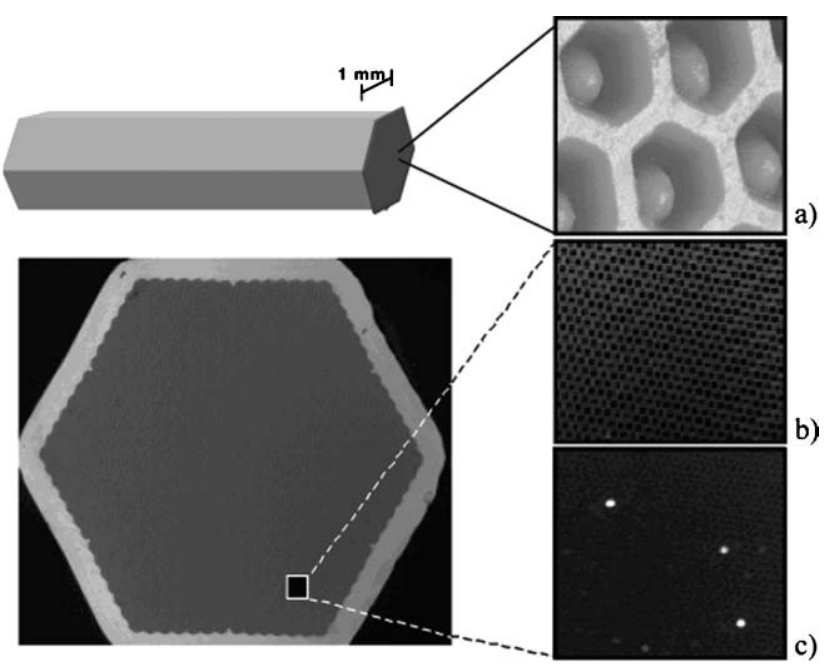

Fig. 31 General overview of the fiber optic array platform. (a) The 1 -mm diameter, hexagonally packed optical fiber bundle is comprised of $\sim 50000$ individual $3.1 \mu \mathrm{m}$ diameter fibers. The fibers are etched, and bead sensors are added to the etched fiber face. (b) A white-light image with no fluorescent targets in the array. (c) An image with fluorescent targets hybridized to the array. (Reprinted with permission from ref. 305. Copyright 2003, American Chemical Society.) groups have developed high-density microarray optical sensors for explosive-like vapors, ${ }^{3,83,299}$ metal ions, ${ }^{304}$ and bio-sensors. ${ }^{305,306}$ In a similar approach McDevitt and coworkers used polystyrene-poly(ethylene glycol) and agarose microspheres arranged in micromachined cavities etched in silicon wafers for analysis of beverages. ${ }^{295}$ Indicator molecules are covalently attached to the polymeric microspheres and identification of acids, bases, metal cations, metabolic cofactors, and antibody reagents was done by analysis of the fluorescence or colorimetric changes extracted from digital images obtained with a CCD device.

Recently Wolfbeis and co-workers have developed cross reactive sensor arrays in microtiter plate format, in which determination of mixtures of divalent metal ions were performed. $^{68,307}$

\section{Conclusions and outlook}

In this review, a large number of different approaches for the development of new materials for fluorescent chemical sensing have been discussed. However, there is still a need of sensors for many different targets. The production of new fluorescent functional materials able to report continuously and reversibly chemical recognition events plays an important role in the development of chemical sensors since the sensor performance depends very much on the properties of the material. Thus, for the successful design of a sensing scheme the first step is the selection of the most suitable material for the target analyte recognition and the device implementation. Many different approaches to the design of these materials are possible due to (i) the large variety of substrates $e . g$. polymers, mesoporous materials, sol-gels, glasses, gold, silica particles, and quantum dots, etc. (ii) the variety in the recognition motifs, (iii) the probe immobilization methods, (iv) the required sensor sizes, and (v) the diversity of target analytes. On the other hand, the miniaturization of the sensing probes for the fabrication of non-invasive and non-toxic nanosensors is very important in the field of analytical studies in bio and chemical systems.

From the examples published in literature, covalent immobilization of fluorescent probes to several materials has been proven very useful in terms of device implementation because it allows the production of stable and reusable materials. Additionally, combinatorial methods and the fabrication of sensor arrays, either to select the best system or to enhance the performance of non-selective systems by the fabrication of cross-reactive sensor arrays, are paving the way towards efficient sensors. Among the possible substrates, immobilization of the sensing probes on glass surfaces will produce efficient arrays of fluorescent chemosensors because of their simplicity, efficiency, and high stability. Similar to protein and DNA microchips, high-density microarray sensors on glass slides for environmental sensing and food control are easily envisioned. Due to the fact that multianalyte sensors and on-line monitoring are requirements for sensor design, microfluidics devices (hardly used yet for sensing), appear as a future direction in the development of sensors due to their small size and the possibility of on-line monitoring performance. $^{222}$ 


\section{References}

1 B. R. Eggins, Chemical Sensors and Biosensors (Analytical Techniques in the Sciences), John Wiley \& Sons Ltd, Chichester, UK, 2002.

2 H. F. Lodish, Molecular Cell Biology, W. H. Freeman \& Company, New York, 5th edn, 2004.

3 K. J. Albert and D. R. Walt, Anal. Chem., 2000, 72, 1947-1955.

4 R. J. Colton and J. N. Russell, Science, 2003, 299, 1324-1325.

5 J. S. Yang and T. M. Swager, J. Am. Chem. Soc., 1998, 120, 11864-11873.

6 E. Kress-Rogers and C. J. B. Brimelow, Instrumentation and Sensors in the Food Industry, Woodhead Publishing Ld, Cambridge, 2nd edn, 2001.

7 Sensors Update, Wiley-VCH Verlag GmbH \& Co, KGaA, Weinheim, 2003.

8 A. W. Czarnik, Chem. Biol., 1995, 2, 423-428.

9 J. R. Lakowicz, Topics in Fluorescence Spectroscopy, vol. 2, Principles, Plenum Press, New York, 1991.

10 J. R. Lakowicz, Topics in Fluorescence Spectroscopy, vol. 4, Techniques, Plenum Press, New York, 1991.

11 J. R. Lakowicz, Topics in Fluorescence Spectroscopy, vol. 3, Application, Plenum Press, New York, 1991.

12 D. J. Irvine, M. A. Purbhoo, M. Krogsgaard and M. M. Davis, Nature, 2002, 419, 845-849.

13 A. J. Pope, U. M. Haupts and K. J. Moore, Drug Discovery Today, 1999, 4, 350-362.

14 R. Y. Tsien, Biochemistry, 1980, 19, 2396-2404.

15 G. Grynkiewicz, M. Poenie and R. Y. Tsien, J. Biol. Chem., 1985, 260, 3440-3450.

16 B. Valeur and I. Leray, Coord. Chem. Rev., 2000, 205, 3-40.

17 S. Wang, W. Shen, Y. L. Feng and H. Tian, Chem. Commun., 2006, 1497-1499.

18 J. F. Callan, A. P. De Silva and D. C. Magri, Tetrahedron, 2005, 61, 8551-8588.

19 S. Xu, K. C. Chen and H. Tian, J. Mater. Chem., 2005, 15, 2676-2680.

20 J. W. Bell and N. M. Hext, Chem. Soc. Rev., 2004, 33, 589-598.

21 O. S. Wolfbeis, J. Mater. Chem., 2005, 15, 2657-2669.

22 J. P. Desvergne and A. W. Czarnik.Chemosensors of Ion and Molecule Recognition (NATO Science Series, Serie C: Mathematical and Physical Sciences), Kluwer Academic, London, 1997.

23 Fluorescent Chemosensors for Ion and Molecule Recognition, American Chemical Society, Washington DC, 1993, vol. 538.

24 P. Buhlmann, E. Pretsch and E. Bakker, Chem. Rev., 1998, 98, 1593-1687.

25 J. R. Epstein, I. Biran and D. R. Walt, Anal. Chim. Acta, 2002, 469, 3-36.

26 F. J. Steemers, J. A. Ferguson and D. R. Walt, Nat. Biotechnol., 2000, 18, 91-94.

27 R. M. De Lorimier, J. J. Smith, M. A. Dwyer, L. L. Looger, K. M. Sali, C. D. Paavola, S. S. Rizk, S. Sadigov, D. W. Conrad, L. Loew and H. W. Hellinga, Protein Sci., 2002, 11, 2655-2675.

28 H. W. Hellinga and J. S. Marvin, Trends Biotechnol., 1998, 16, 183-189.

29 J. W. Aylott, Analyst, 2003, 128, 309-312.

30 A. P. de Silva, H. Q. N. Gunaratne, T. Gunnlaugsson, A. J. M. Huxley, C. P. Mccoy, J. T. Rademacher and T. E. Rice, Chem. Rev., 1997, 97, 1515-1566.

31 E. U. Akkaya, M. E. Huston and A. W. Czarnik, J. Am. Chem. Soc., 1990, 112, 3590-3593.

32 S. Y. Liu, Y. B. He, G. Y. Qing, K. X. Xu and H. J. Qin, Tetrahedron: Asymmetry, 2005, 16, 1527-1534.

33 L. Z. Meng, G. X. Mei, Y. B. He and Z. Y. Zeng, Acta Chim. Sinica, 2005, 63, 416-420.

34 J. Y. Lee, S. K. Kim, J. H. Jung and J. S. Kim, J. Org. Chem., 2005, 70, 1463-1466.

35 M. E. Huston, C. Engleman and A. W. Czarnik, J. Am. Chem. Soc., 1990, 112, 7054-7056.

36 S. L. Wiskur, H. Ait-Haddou, J. J. Lavigne and E. V. Anslyn, Acc. Chem. Res., 2001, 34, 963-972.

37 M. A. Hortala, L. Fabbrizzi, N. Marcotte, F. Stomeo and A. Taglietti, J. Am. Chem. Soc., 2003, 125, 20-21.

38 S. L. Tobey and E. V. Anslyn, Org. Lett., 2003, 5, 2029-2031.
39 A. Buryak and K. Severin, Angew. Chem., Int. Ed., 2004, 43, 4771-4774.

40 Y. Kubo, A. Kobayashi, T. Ishida, Y. Misawa and T. D. James, Chem. Commun., 2005, 2846-2848.

41 I. Yoshimura, Y. Miyahara, N. Kasagi, H. Yamane, A. Ojida and I. Hamachi, J. Am. Chem. Soc., 2004, 126, 12204-12205.

42 S. C. Zimmerman and N. G. Lemcoff, Chem. Commun., 2004, 5-14.

43 M. Arduini, S. Marcuz, M. Montolli, E. Rampazzo, F. Mancin, S. Gross, L. Armelao, P. Tecilla and U. Tonellato, Langmuir, 2005, 21, 9314-9321.

44 M. Crego-Calama and D. N. Reinhoudt, Adv. Mater., 2001, 13, 1171-1174.

45 K. A. Gattas-Asfura and R. M. Leblanc, Chem. Commun., 2003, 2684-2685.

46 Y. Zheng, J. Orbulescu, X. Ji, F. M. Andreopoulos, S. M. Pham and R. M. Leblanc, J. Am. Chem. Soc., 2003, 125, 2680-2686.

47 S. Kolusheva, O. Molt, M. Herm, T. Schrader and R. Jelinek, J. Am. Chem. Soc., 2005, 127, 10000-10001.

48 K. P. McNamara, N. Rosenzweig and Z. Rosenzweig, Mikrochim. Acta, 1999, 131, 57-64.

49 R. Aucejo, J. Alarcón, C. Soriano, M. C. Guillén, E. GarcíaEspańa and F. Torres, J. Mater. Chem., 2005, 15, 2920-2927.

50 O. S. Wolfbeis, Anal. Chem., 2004, 76, 3269-3283.

51 R. A. Potyrailo, S. E. Hobbs and G. M. Hieftje, Fresenius' J. Anal. Chem., 1998, 362, 349-373.

52 M. Zourob, S. Mohr, P. R. Fielden and N. J. Goddard, Lab Chip, 2005, 5, 772-777.

53 R. Meallet-Renault, R. Pansu, S. Amigoni-Gerbier and C. Larpent, Chem. Commun., 2004, 2344-2345.

54 J. T. Suri, D. B. Cordes, F. E. Cappuccio, R. A. Wessling and B. Singaram, Angew. Chem., Int. Ed., 2003, 42, 5857-5859.

55 S. H. Lee, J. Kumar and S. K. Tripathy, Langmuir, 2000, 16, 10482-10489.

56 B. Adhikari and S. Majumdar, Prog. Polym. Sci., 2004, 29, 699-766.

57 Y. Amao, Microchim. Acta, 2003, 143, 1-12.

58 K. J. Albert, S. D. Gill, T. C. Pearce and D. R. Walt, Anal. Bioanal. Chem., 2002, 373, 792-802.

59 T. A. Dickinson, D. R. Walt, J. White and J. S. Kauer, Anal. Chem., 1997, 69, 3413-3418.

60 P. Bosch, F. Catalina, T. Corrales and C. Peinado, Chem. Eur. J., $2005,11,4314-4325$.

61 Y. Amao, K. Asai, I. Okura, H. Shinohara and H. Nishide, Analyst, 2000, 125, 1911-1914.

62 Y. Zhang, R. H. Yang, F. Liu and K. A. Li, Anal. Chem., 2004, 76, 7336-7345.

63 E. L. Doyle, C. A. Hunter, H. C. Phillips, S. J. Webb and N. H. Williams, J. Am. Chem. Soc., 2003, 125, 4593-4599.

64 W. Qin, P. Parzuchowski, W. Zhang and M. E. Meyerhoff, Anal. Chem., 2003, 75, 332-340.

65 Y. Liu, R. C. Mills, J. M. Boncella and K. S. Schanze, Langmuir, 2001, 17, 7452-7455.

66 T. M. Ambrose and M. E. Meyerhoff, Anal. Chim. Acta, 1999, 378, 119-126.

67 M. R. Shortreed, S. Dourado and R. Kopelman, Sens. Actuators, $B, 1997, \mathbf{3 8}, 8-12$.

68 T. Mayr, G. Liebsch, I. Klimant and O. S. Wolfbeis, Analyst, 2002, 127, 201-203.

69 J. Lin, TrAC-Trends Anal. Chem., 2000, 19, 541-552.

70 B. M. Weidgans, C. Krause, I. Klimant and O. S. Wolfbeis, Analyst, 2004, 129, 645-650.

71 A. Ceresa, Y. Qin, S. Peper and E. Bakker, Anal. Chem., 2003, 75, 133-140.

72 H. G. Zhu and M. J. Mcshane, Abstr. Pap. Am. Chem. Soc., 2005, 230, U3640-U3641.

73 T. Buranda, J. M. Huang, V. H. Pérez-Luna, B. Schreyer, L. A. Sklar and G. P. López, Anal. Chem., 2002, 74, 1149-1156.

74 H. R. Kermis, Y. Kostov, P. Harms and G. Rao, Biotechnol. Prog., 2002, 18, 1047-1053.

75 S. M. Buck, H. Xu, M. Brasuel, M. A. Philbert and R. Kopelman, Talanta, 2004, 63, 41-59.

76 R. M. Sanchez-Martin, M. Cuttle, S. Mittoo and M. Bradley, Angew. Chem., Int. Ed., 2006, 45, 5472-5474. 
77 E. Brasola, F. Mancin, E. Rampazzo, P. Tecilla and U. Tonellato, Chem. Commun., 2003, 3026-3027.

78 O. S. Wolfbeis, N. V. Rodríguez and T. Werner, Mikrochim. Acta, 1992, 108, 133-141.

79 T. Tanabe, K. Touma, K. Hamasaki and A. Ueno, Anal. Chem., 2001, 73, 3126-3130.

80 T. Tanabe, K. Touma, K. Hamasaki and A. Ueno, Anal. Chem., 2001, 73, 1877-1880.

81 S. M. Barnard and D. R. Walt, Nature, 1991, 353, 338-340.

82 J. A. Ferguson, B. G. Healey, K. S. Bronk, S. M. Barnard and D. R. Walt, Anal. Chim. Acta, 1997, 340, 123-131.

83 J. R. Epstein and D. R. Walt, Chem. Soc. Rev., 2003, 32, 203-214.

84 J. A. Ferguson, F. J. Steemers and D. R. Walt, Anal. Chem., 2000, 72, 5618-5624.

85 W. H. Liu, Y. Wang, J. H. Tang, G. L. Shen and R. Q. Yu, Analyst, 1998, 123, 365-369.

86 B. S. Sandanaraj, R. Demont, S. V. Aathimanikandan, E. N. Savariar and S. Thayumanavan, J. Am. Chem. Soc., 2006, 128, 10686-10687.

87 J. J. Lavigne, S. Savoy, M. B. Clevenger, J. E. Ritchie, B. Mcdoniel, S. J. Yoo, E. V. Anslyn, J. T. McDevitt, J. B. Shear and D. Neikirk, J. Am. Chem. Soc., 1998, 120, 6429-6430.

88 U. Kosch, I. Klimant, T. Werner and O. S. Wolfbeis, Anal. Chem., 1998, 70, 3892-3897.

89 I. Grabchev, X. H. Qian, Y. Xiao and R. Zhang, New J. Chem., 2002, 26, 920-925.

90 X. D. Ge, Y. Kostov and G. Rao, Biosens. Bioelectron., 2003, 18, 857-865.

91 Y. Koshi, E. Nakata, H. Yamane and I. Hamachi, J. Am. Chem. Soc., 2006, 128, 10413-10422.

92 E. V. López, G. P. Luis, J. L. Suarez-Rodríguez, I. A. Rivero and M. E. Díaz-García, Sens. Actuators, B, 2003, 90, 256-263.

93 H. R. He, M. A. Mortellaro, M. J. P. Leiner, R. J. Fraatz and J. K. Tusa, J. Am. Chem. Soc., 2003, 125, 1468-1469.

94 V. Balzani, P. Ceroni, M. Maestri, C. Saudan and V. Vicinelli, Top. Curr. Chem., 228, 159-191.

95 V. Balzani, P. Ceroni, S. Gestermann, C. Kauffmann, M. Gorka and F. Vogtle, Chem. Commun., 2000, 853-854.

96 V. J. Pugh, Q. S. Hu and L. Pu, Angew. Chem., Int. Ed., 2000, 39, 3638-3641.

97 L. Pu, J. Photochem. Photobiol., A, 2003, 155, 47-55.

98 L. Z. Gong, Q. S. Hu and L. Pu, J. Org. Chem., 2001, 66, 2358-2367.

99 F. Vogtle, S. Gestermann, C. Kauffmann, P. Ceroni, V. Vicinelli and V. Balzani, J. Am. Chem. Soc., 2000, 122, 10398-10404.

100 I. Grabchev, J. M. Chovelon, V. Bojinov and G. Ivanova, Tetrahedron, 2003, 59, 9591-9598.

101 I. Grabchev, J. M. Chovelon and X. H. Qian, New J. Chem., 2003, 27, 337-340.

102 D. Batra and K. J. Shea, Curr. Opin. Chem. Biol., 2003, 7, $434-442$

103 F. H. Dickey, Proc. Natl. Acad. Sci. USA, 1949, 35, 227-229.

104 K. Haupt and K. Mosbach, Chem. Rev., 2000, 100, 2495-2504.

105 P. Turkewitsch, B. Wandelt, G. D. Darling and W. S. Powell, Anal. Chem., 1998, 70, 2025-2030.

106 A. L. Jenkins, O. M. Uy and G. M. Murray, Anal. Chem., 1999, 71, 373-378

107 Y. Liao, W. Wang and B. H. Wang, Bioorg. Chem., 1999, 27, 463-476.

108 N. T. K. Thanh, D. L. Rathbone, D. C. Billington and N. A. Hartell, Anal. Lett., 2002, 35, 2499-2509.

109 A. J. Tong, H. Dong and L. D. Li, Anal. Chim. Acta, 2002, 466, 31-37.

110 W. Wang, S. H. Gao and B. H. Wang, Org. Lett., 1999, 1, 1209-1212.

111 S. Subrahmanyam, S. A. Piletsky, E. V. Piletska, B. N. Chen, K. Karim and A. P. F. Turner, Biosens. Bioelectron., 2001, 16, 631-637.

112 S. H. Gao, W. Wang and B. H. Wang, Bioorg. Chem., 2001, 29, 308-320

113 D. L. Rathbone, D. Q. Su, Y. F. Wang and D. C. Billington, Tetrahedron Lett., 2000, 41, 123-126.

114 J. Matsui, M. Higashi and T. Takeuchi, J. Am. Chem. Soc., 2000, 122, 5218-5219.
115 B. Wandelt, P. Turkewitsch, S. Wysocki and G. D. Darling, Polymer, 2002, 43, 2777-2785.

116 H. Q. Zhang, W. Verboom and D. N. Reinhoudt, Tetrahedron Lett., 2001, 42, 4413-4416.

117 H. Kubo, N. Yoshioka and T. Takeuchi, Org. Lett., 2005, 7, 359-362.

118 N. T. Greene and K. D. Shimizu, J. Am. Chem. Soc., 2005, 127, $5695-5700$.

119 Q. Zhou and T. M. Swager, J. Am. Chem. Soc., 1995, 117, 12593-12602.

120 T. M. Swager, Acc. Chem. Res., 1998, 31, 201-207.

121 F. He, Y. L. Tang, M. H. Yu, F. Feng, L. L. An, H. Sun, S. Wang, Y. L. Li, D. B. Zhu and G. C. Bazan, J. Am. Chem. Soc., 2006, 128, 6764-6765.

122 J. W. Hong, W. L. Henme, G. E. Keller, M. T. Rinke and G. C. Bazan, Adv. Mater., 2006, 18, 878-882.

123 B. Liu and G. C. Bazan, J. Am. Chem. Soc., 2006, 128, 1188-1196.

124 B. Liu and G. C. Bazan, Chem. Mater., 2004, 16, 4467-4476.

125 Q. H. Xu, B. S. Gaylord, S. Wang, G. C. Bazan, D. Moses and A. J. Heeger, Proc. Natl. Acad. Sci. USA, 2004, 101, 11634-11639.

126 S. Wang and G. C. Bazan, Adv. Mater., 2003, 15, 1425-1428.

127 B. Wang and M. R. Wasielewski, J. Am. Chem. Soc., 1997, 119, $12-21$.

128 Y. Zhang, C. B. Murphy and W. E. Jones, Macromolecules, 2002, $35,630-636$

129 Z. Chen, C. H. Xue, W. Shi, F. T. Luo, S. Green, J. Chen and H. Y. Liu, Anal. Chem., 2004, 76, 6513-6518.

130 K. B. Crawford, M. B. Goldfinger and T. M. Swager, J. Am. Chem. Soc., 1998, 120, 5187-5192.

131 I. B. Kim and U. H. F. Bunz, J. Am. Chem. Soc., 2006, 128, 2818-2819.

132 L. J. Fan and W. E. Jones, J. Am. Chem. Soc., 2006, 128, 6784-6785

133 L. J. Fan, Y. Zhang and W. E. Jones, Macromolecules, 2005, 38, $2844-2849$

$134 \mathrm{H}$. Tong, L. X. Wang, X. B. Jing and F. S. Wang, Macromolecules, 2003, 36, 2584-2586.

135 G. Zhou, Y. X. Cheng, L. X. Wang, X. B. Jing and F. S. Wang, Macromolecules, 2005, 38, 2148-2153.

136 A. Saxena, M. Fujiki, R. Rai, S. Y. Kim and G. Kwak, Macromol. Rapid Commun., 2004, 25, 1771-1775.

137 T. H. Kim and T. M. Swager, Angew. Chem., Int. Ed., 2003, 42, 4803-4806.

138 B. S. Harrison, M. B. Ramey, J. R. Reynolds and K. S. Schanze, J. Am. Chem. Soc., 2000, 122, 8561-8562.

139 F. Naso, F. Babudri, D. Colangiuli, G. M. Farinola, F. Quaranta, R. Rella, R. Tafuro and L. Valli, J. Am. Chem. Soc., 2003, 125, 9055-9061.

140 A. Sundararaman, M. Victor, R. Varughese and F. Jakle, J. Am. Chem. Soc., 2005, 127, 13748-13749.

141 H. Sohn, M. J. Sailor, D. Magde and W. C. Trogler, J. Am. Chem. Soc., 2003, 125, 3821-3830.

142 C. Cumming, M. Fisher and J. Sikes, Electronic Noses and Sensors for the Detection of Explosives, ed. J. W. Gardner and J. Yinon, Kluwer Academic Publishers, Dordrecht, 2004, pp. 53-70.

143 C. J. Cumming, C. Aker, M. Fisher, M. Fox, M. J. La Grone, D. Reust, M. G. Rockley, T. M. Swager, E. Towers and V. Williams, IEEE Trans. Geosci. Remote Sensing, 2001, 39, $1119-1128$.

144 D. T. Mcquade, A. E. Pullen and T. M. Swager, Chem. Rev., 2000, 100, 2537-2574.

145 G. Schulz-Ekloff, D. Wohrle, B. Van Duffel and R. A. Schoonheydt, Microporous Mesoporous Mater., 2002, 51, 91-138.

146 R. Reisfeld, J. Fluoresc., 2002, 12, 317-325.

147 C. Sanchez, B. Lebeau, F. Chaput and J. P. Boilot, Adv. Mater., 2003, 15, 1969-1994.

148 D. A. Loy and K. J. Shea, Chem. Rev., 1995, 95, 1431-1442.

149 C. Sanchez, Soler-Illia Gjda, F. Ribot, T. Lalot, C. R. Mayer and V. Cabuil, Chem. Mater., 2001, 13, 3061-3083.

150 I. Klimant, F. Ruckruh, G. Liebsch, C. Stangelmayer and O. S. Wolfbeis, Mikrochim. Acta, 1999, 131, 35-46.

151 B. Lebeau, C. E. Fowler, S. Mann, C. Farcet, B. Charleux and C. Sanchez, J. Mater. Chem., 2000, 10, 2105-2108. 
152 D. Avnir, D. Levy and R. Reisfeld, J. Phys. Chem., 1984, 88, 5956-5959.

153 M. Plaschke, R. Czolk and H. J. Ache, Anal. Chim. Acta, 1995, 304, 107-113.

154 B. D. Maccraith, C. M. Mcdonagh, G. O'Keeffe, A. K. Mcevoy, T. Butler and F. R. Sheridan, Sens. Actuators, B, 1995, 29, 51-57.

155 G. E. Badini, K. T. V. Grattan and A. C. C. Tseung, Analyst, 1995, 120, 1025-1028.

156 M. Ayadim, J. L. H. Jiwan, A. P. de Silva and J. P. Soumillion, Tetrahedron Lett., 1996, 37, 7039-7042.

157 J. Zilberstein, A. Bromberg and G. Berkovic, J. Photochem. Photobiol., A, 1994, 77, 69-81.

158 G. O'Keeffe, B. D. Maccraith, A. K. Mcevoy, C. M. Mcdonagh and J. F. Mcgilp, Sens. Actuators, B, 1995, 29, 226-230.

159 C. Malins, S. Fanni, H. G. Glever, J. G. Vos and B. D. Maccraith, Anal. Commun., 1999, 36, 3-4.

160 C. Malins, H. G. Glever, T. E. Keyes, J. G. Vos, W. J. Dressick and B. D. Maccraith, Sens. Actuators, B, 2000, 67, 89-95.

161 A. Lobnik, I. Oehme, I. Murkovic and O. S. Wolfbeis, Anal. Chim. Acta, 1998, 367, 159-165.

162 T. Nguyen, K. P. McNamara and Z. Rosenzweig, Anal. Chim. Acta, 1999, 400, 45-54.

163 K. E. Jaeger and M. T. Reetz, Trends Biotechnol., 1998, 16, 396-403.

164 K. P. McNamara, T. Nguyen, G. Dumitrascu, J. Ji, N. Rosenzweig and Z. Rosenzweig, Anal. Chem., 2001, 73, 3240-3246.

165 E. J. Cho and F. V. Bright, Anal. Chim. Acta, 2002, 470, 101-110

166 E. J. Cho and F. V. Bright, Anal. Chem., 2002, 74, 1462-1466.

167 E. J. Cho, Z. Y. Tao, E. C. Tehan and F. V. Bright, Anal. Chem., 2002, 74, 6177-6184.

168 M. Cajlakovic, A. Lobnik and T. Werner, Anal. Chim. Acta, 2002, 455, 207-213.

169 J. M. Haider and Z. Pikramenou, Chem. Soc. Rev., 2005, 34, $120-132$.

170 C. M. Rudzinski, A. M. Young and D. G. Nocera, J. Am. Chem. Soc., 2002, 124, 1723-1727.

171 A. W. Wun, P. T. Snee, Y. T. Chan, M. G. Bawendi and D. G. Nocera, J. Mater. Chem., 2005, 15, 2697-2706.

172 Y. K. Lu and X. P. Yan, Chin. J. Anal. Chem., 2005, 33, 254-260.

173 M. E. Díaz-García and R. B. Laino, Microchim. Acta, 2005, 149, 19-36.

174 M. K. P. Leung, C. F. Chow and M. H. W. Lam, J. Mater. Chem., 2001, 11, 2985-2991.

175 A. L. Graham, C. A. Carlson and P. L. Edmiston, Anal. Chem., 2002, 74, 458-467.

176 C. T. Kresge, M. E. Leonowicz, W. J. Roth, J. C. Vartuli and J. S. Beck, Nature, 1992, 359, 710-712.

177 K. Möller and T. Bein, Chem. Mater., 1998, 10, 2950-2963.

178 J. L. Shi, Z. L. Hua and L. X. Zhang, J. Mater. Chem., 2004, 14, 795-806.

179 Q. M. Zhang, K. Ariga, A. Okabe and T. Aida, J. Am. Chem. Soc., 2004, 126, 988-989.

180 S. Huh, J. W. Wiench, B. G. Trewyn, S. Song, M. Pruski and V. S. Y. Lin, Chem. Commun., 2003, 2364-2365.

181 B. J. Scott, G. Wirnsberger and G. D. Stucky, Chem. Mater., 2001, 13, 3140-3150

182 T. Pellegrino, S. Kudera, T. Liedl, A. M. Javier, L. Manna and W. J. Parak, Small, 2005, 1, 48-63.

183 G. Wirnsberger, B. J. Scott and G. D. Stucky, Chem. Commun., 2001, 119-120.

184 H. Y. Fan, Y. F. Lu, A. Stump, S. T. Reed, T. Baer, R. Schunk, V. Pérez-Luna, G. P. Lopez and C. J. Brinker, Nature, 2000, 405, $56-60$.

185 A. B. Descalzo, D. Jimenez, M. D. Marcos, R. Martínez-Máńez, J. Soto, J. El Haskouri, C. Guillem, D. Beltran, P. Amoros and M. V. Borrachero, Adv. Mater., 2002, 14, 966-969.

186 A. B. Descalzo, M. D. Marcos, R. Martínez-Máńez, J. Soto, D. Beltran and P. Amoros, J. Mater. Chem., 2005, 15, 2965-2973.

187 V. S. Y. Lin, C. Y. Lai, J. G. Huang, S. A. Song and S. Xu, J. Am. Chem. Soc., 2001, 123, 11510-11511.

188 D. R. Radu, C. Y. Lai, J. W. Wiench, M. Pruski and V. S. Y. Lin, J. Am. Chem. Soc., 2004, 126, 1640-1641.

189 M. Wark, Y. Rohlfing, Y. Altindag and H. Wellmann, Phys. Chem. Chem. Phys., 2003, 5, 5188-5194.
190 A. B. Descalzo, K. Rurack, H. Weisshoff, R. Martínez-Máńez, M. D. Marcos, P. Amoros, K. Hoffmann and J. Soto, J. Am. Chem. Soc., 2005, 127, 184-200.

191 R. Metivier, I. Leray, B. Lebau and B. Valeur, J. Mater. Chem., 2005, 15, 2965-2973.

192 M. Comes, G. Rodríguez-López, M. D. Marcos, R. MartínezMáñez, F. Sancenón, J. Soto, L. A. Villaescusa, P. Amorós and D. Beltrán, Angew. Chem., Int. Ed., 2005, 44, 2918-2922.

193 O. S. Wolfbeis and B. P. H. Schaffar, Anal. Chim. Acta, 1987, 198, $1-12$.

194 P. Grandini, F. Mancin, P. Tecilla, P. Scrimin and U. Tonellato, Angew. Chem., Int. Ed., 1999, 38, 3061-3064.

195 Y. D. Fernandez, A. P. Gramatges, V. Amendola, F. Foti, C. Mangano, P. Pallavicini and S. Patroni, Chem. Commun., 2004, $1650-1651$.

196 Y. Díaz-Fernandez, A. Pérez-Gramatges, S. Rodríguez-Calvo, C. Mangano and P. Pallavicini, Chem. Phys. Lett., 2004, 398 , 245-249.

197 F. Mancin, E. Rampazzo, P. Tecilla and U. Tonellato, Chem. Eur J., 2006, 12, 1844-1854.

198 D. Y. Sasaki, D. R. Shnek, D. W. Pack and F. H. Arnold, Angew. Chem., Int. Ed. Engl., 1995, 34, 905-907.

199 Y. Diaz-Fernandez, F. Foti, C. Mangano, P. Pallavicini, S. Patroni, A. Perez-Gramatges and S. Rodriguez-Calvo, Chem. Eur. J., 2006, 12, 921-930.

200 R. M. Crooks and A. J. Ricco, Acc. Chem. Res., 1998, 31, 219-227.

201 V. Chechik, R. M. Crooks and C. J. M. Stirling, Adv. Mater., 2000, 12, 1161-1171.

202 E. Dulkeith, A. C. Morteani, T. Niedereichholz, T. A. Klar, J. Feldmann, S. A. Levi, F. C. J. M. Van Veggel, D. N. Reinhoudt, M. Möller and D. I. Gittins, Phys. Rev. Lett., 2002, 89, 203002.

203 H. Imahori, H. Norieda, Y. Nishimura, I. Yamazaki, K. Higuchi, N. Kato, T. Motohiro, H. Yamada, K. Tamaki, M. Arimura and Y. Sakata, J. Phys. Chem. B, 2000, 104, 1253-1260.

204 K. Motesharei and D. C. Myles, J. Am. Chem. Soc., 1994, 116, $7413-7414$

205 X. Y. Sun, B. Liu and Y. B. Jiang, Anal. Chim. Acta, 2004, 515, 285-290.

206 R. C. Panicker, X. Huang and S. Q. Yao, Comb. Chem. High Throughput Screening, 2004, 7, 547-556.

207 D. P. Walsh and Y. T. Chang, Comb. Chem. High Throughput Screening, 2004, 7, 557-564.

208 A. Adronov, D. R. Robello and J. M. J. Frechet, J. Polym. Sci., Part A: Polym. Chem., 2001, 39, 1366-1373.

209 L. A. J. Chrisstoffels, A. Adronov and J. M. J. Frechet, Angew. Chem., Int. Ed., 2000, 39, 2163-2167.

210 L. A. Saari and W. R. Seitz, Anal. Chem., 1982, 54, 821.

211 B. G. Harper, Anal. Chem., 1975, 47, 348.

212 E. Urbano, H. Offenbacher and O. S. Wolfbeis, Anal. Chem. Abstr., 1984, 56, 427-429.

213 M. P. Xavier, D. García-Fresnadillo, M. C. Moreno-Bondi and G. Orellana, Anal. Chem., 1998, 70, 5184-5189.

214 T. P. Sullivan and W. T. S. Huck, Eur. J. Org. Chem., 2003 , $17-29$.

215 S. Flink, F. C. J. M. Van Veggel and D. N. Reinhoudt, Chem. Commun., 1999, 2229-2230.

216 N. J. Van der Veen, S. Flink, M. A. Deij, R. J. M. Egberink, F. C. J. M. Van Veggel and D. N. Reinhoudt, J. Am. Chem. Soc., 2000, 122, 6112-6113.

217 T. Van der Boom, G. Evmenenko, P. Dutta and M. R. Wasielewski, Chem. Mater., 2005, 15, 4068-4074.

218 L. Basabe Desmonts, Fluorescent Self-Assembled Monolayers As New Sensing Materials, Wohrmann Print Service, The Netherlands, 2005

219 L. Basabe-Desmonts, J. Beld, R. S. Zimmerman, J. Hernando, P. Mela, M. F. G. Parajó, N. F. Van Hulst, A. Van den Berg, D. N. Reinhoudt and M. Crego-Calama, J. Am. Chem. Soc., 2004, 126, 7293-7299.

220 R. S. Zimmerman, L. Basabe-Desmonts, F. Van der Baan, D. N. Reinhoudt and M. Crego-Calama, J. Mater. Chem., 2005, 15, 2772-2777.

221 L. Basabe-Desmonts, D. N. Reinhoudt and M. Crego-Calama, Adv. Mater., 2006, 18, 1028-1032. 
222 P. Mela, S. Onclin, M. H. Goedbloed, S. Levi, M. F. GarcíaParajó, N. F. Van Hulst, B. J. Ravoo, D. N. Reinhoudt and A. Van den Berg, Lab Chip, 2005, 5, 163-170.

223 M. A. Cejas and F. M. Raymo, Langmuir, 2005, 21, 5795-5802.

224 N. Nath and A. Chilkoti, J. Fluoresc., 2004, 14, 377-389.

225 J. J. Shi, Y. F. Zhu, X. R. Zhang, W. R. G. Baeyens and A. M. García-Campana, TrAC-Trends Anal. Chem., 2004, 23, 351-360

226 U. Drechsler, B. Erdogan and V. M. Rotello, Chem. Eur. J., 2004, 10, 5570-5579.

227 M. Montalti, L. Prodi and N. Zaccheroni, J. Mater. Chem., 2005, 15, 2810-2814

228 M. Montalti, L. Prodi, N. Zacheroni, A. Zattoni, P. Reschiglian and G. Falini, Langmuir, 2004, 20, 2989-2991.

229 Y. F. Chen and Z. Rosenzweig, Anal. Chem., 2002, 74, 5132-5138.

230 K. Sasaki, Z. Y. Shi, R. Kopelman and H. Masuhara, Chem. Lett., 1996, 141-142.

231 M. Montalti, L. Prodi, N. Zaccheroni and G. Falini, J. Am. Chem. Soc., 2002, 124, 13540-13546.

232 A. Rose, Z. G. Zhu, C. F. Madigan, T. M. Swager and V. Bulovic, Nature, 2005, 434, 876-879.

233 E. Rampazzo, E. Brasola, S. Marcuz, F. Mancin, P. Tecilla and U. Tonellato, J. Mater. Chem., 2005, 15, 2687-2696.

234 R. C. Major and X. Y. Zhu, J. Am. Chem. Soc., 2003, 125, 8454-8455.

235 L. Jacak, P. Hawrylak and A. Wojs, Quantum Dots, Springer, Berlin, 1998

236 J. R. Lakowicz, I. Gryczynski, Z. Gryczynski and C. J. Murphy, J. Phys. Chem. B, 1999, 103, 7613-7620.

237 M. Bruchez, M. Moronne, P. Gin, S. Weiss and A. P. Alivisatos, Science, 1998, 281, 2013-2016.

238 G. Kalyuzhny and R. W. Murray, J. Phys. Chem. B, 2005, 109, 7012-7021.

239 Z. B. Lin, X. G. Su, Y. Mu and Q. H. Jin, J. Nanosci. Nanotechnol., 2004, 4, 641-645.

240 D. M. Willard, T. Mutschler, M. Yu, J. Jung and A. Van Orden, Anal. Bioanal. Chem., 2006, 384, 564-571.

241 J. M. Costa-Fernandez, R. Pereiro and A. Sanz-Medel, TrACTrends Anal. Chem., 2006, 25, 207-218.

242 W. C. W. Chan and S. M. Nie, Science, 1998, 281, 2016-2018.

243 I. L. Medintz, H. T. Uyeda, E. R. Goldman and H. Mattoussi, Nat. Mater., 2005, 4, 435-446.

244 L. Wang, L. Y. Wang, C. Q. Zhu, X. W. Wei and X. W. Kan, Anal. Chim. Acta, 2002, 468, 35-41.

245 X. Michalet, F. Pinaud, T. D. Lacoste, M. Dahan, M. P. Bruchez, A. P. Alivisatos and S. Weiss, Single Mol., 2001, 2, 261-276.

246 L. Y. Wang, L. Wang, F. Gao, Z. Y. Yu and Z. M. Wu, Analyst, 2002, 127, 977-980.

247 J. G. Liang, X. P. Ai, Z. K. He and D. W. Pang, Analyst, 2004, 129, 619-622.

248 C. Bo and Z. Ping, Anal. Bioanal. Chem., 2005, 381, 986-992.

249 W. J. Jin, J. M. Costa-Fernandez, R. Pereiro and A. Sanz-Medel, Anal Chim Acta, 2004, 522, 1-8.

250 W. J. Jin, M. T. Fernandez-Arguelles, J. M. Costa-Fernandez, R. Pereiro and A. Sanz-Medel, Chem. Commun., 2005, 883-885.

251 T. Jin, F. Fujii, H. Sakata, M. Tamura and M. Kinjo, Chem. Commun., 2005, 4300-4302.

252 D. B. Cordes, S. Gamsey and B. Singaram, Angew. Chem., Int. Ed., 2006, 45, 3829-3832.

253 T. Torimoto, H. Kontani, Y. Shibutani, S. Kuwabata, T. Sakata, H. Mori and H. Yoneyama, J. Phys. Chem. B, 2001, 105, $6838-6845$

254 K. Iwasaki, T. Torimoto, T. Shibayama, T. Nishikawa and B. Ohtani, Small, 2006, 2, 854-858.

255 R. E. Galian, M. Laferriere and J. C. Scaiano, J. Mater. Chem., 2006, 16, 1697-1701.

256 K. Konishi and T. Hiratani, Angew. Chem., Int. Ed., 2006, 45, 5191-5194

257 J. Z. Lu and Z. Rosenzweig, Fresenius' J. Anal. Chem., 2000, 366, $569-575$

258 H. A. Clark, S. L. R. Barker, M. Brasuel, M. T. Miller, E. Monson, S. Parus, Z. Y. Shi, A. Song, B. Thorsrud, R. Kopelman, A. Ade, W. Meixner, B. Athey, M. Hoyer, D. Hill, R. Lightle and M. A. Philbert, Sens. Actuators, B, 1998, 51, 12-16.
259 S. M. Buck, Y. E. L. Koo, E. Park, H. Xu, M. A. Philbert, M. A. Brasuel and R. Kopelman, Curr. Opin. Chem. Biol., 2004, 8, 540-546.

260 H. Xu, J. W. Aylott, R. Kopelman, T. J. Miller and M. A. Philbert, Anal. Chem., 2001, 73, 4124-4133.

261 J. P. Sumner and R. Kopelman, Analyst, 2005, 130, 528-533.

262 T. Nguyen and Z. Rosenzweig, Anal. Bioanal. Chem., 2002, 374, 69-74.

263 K. P. McNamara and Z. Rosenzweig, Anal. Chem., 1998, 70, 4853-4859.

264 A. H. Ma and Z. Rosenzweig, Anal. Bioanal. Chem., 2005, 382, $28-36$.

265 R. H. Baughman, A. A. Zakhidov and W. A. De Heer, Science, 2002, 297, 787-792.

266 C. Ehli, G. M. A. Rahman, N. Jux, D. Balbinot, D. M. Guldi, F. Paolucci, M. Marcaccio, D. Paolucci, M. Melle-Franco, F. Zerbetto, S. Campidelli and M. Prato, J. Am. Chem. Soc, 2006, 128, 11222-11231.

267 S. S. Wong, E. Joselevich, A. T. Woolley, C. L. Cheung and C. M. Lieber, Nature, 1998, 394, 52-55.

268 J. Lefebvre, J. M. Fraser, Y. Homma and P. Finnie, Appl. Phys. A: Mater. Sci. Process., 2004, 78, 1107-1110.

269 M. S. Strano, C. B. Huffman, V. C. Moore, M. J. O'Connell, E. H. Haroz, J. Hubbard, M. Miller, K. Rialon, C. Kittrell, S. Ramesh, R. H. Hauge and R. E. Smalley, J. Phys. Chem. B, 2003, 107, 6979-6985.

270 G. Dukovic, B. E. White, Z. Y. Zhou, F. Wang, S. Jockusch, M. L. Steigerwald, T. F. Heinz, R. A. Friesner, N. J. Turro and L. E. Brus, J. Am. Chem. Soc., 2004, 126, 15269-15276.

271 P. W. Barone, S. Baik, D. A. Heller and M. S. Strano, Nat. Mater., 2005, 4, 86-116.

272 J. J. Lavigne and E. V. Anslyn, Angew. Chem., Int. Ed., 2001, 40, 3119-3130.

273 G. Gauglitz, Curr. Opin. Chem. Biol., 2000, 4, 351-355.

274 F. Szurdoki, D. H. Ren and D. R. Walt, Anal. Chem., 2000, 72, $5250-5257$.

275 A. Singh, Q. W. Yao, L. Tong, W. C. Still and D. Sames, Tetrahedron Lett., 2000, 41, 9601-9605.

276 S. E. Schneider, S. N. O'Neil and E. V. Anslyn, J. Am. Chem. Soc., 2000, 122, 542-543.

277 E. J. Iorio, Y. F. Shao, C. T. Chen, H. Wagner and W. C. Still, Bioorg. Med. Chem. Lett., 2001, 11, 1635-1638.

278 C. T. Chen, H. Wagner and W. C. Still, Science, 1998, 279, $851-853$

279 H. Hioki, M. Kubo, H. Yoshida, M. Bando, Y. Ohnishi and M. Kodama, Tetrahedron Lett., 2002, 43, 7949-7952.

280 C. J. Davis, P. T. Lewis, M. E. Mccarroll, M. W. Read, R. Cueto and R. M. Strongin, Org. Lett., 1999, 1, 331-334.

281 T. D. James, Sandanayake Kras and S. Shinkai, Angew. Chem. Int. Ed. Engl., 1996, 35, 1911-1922.

282 Y. Lu, J. W. Liu, J. Li, P. J. Bruesehoff, C. M. B. Pavot and A. K. Brown, Biosens. Bioelectron., 2003, 18, 529-540.

283 M. Castillo and I. A. Rivero, Arkivoc, 2003, 193-202.

284 D. Leipert, D. Nopper, M. Bauser, G. Gauglitz and G. Jung, Angew. Chem., Int. Ed., 1998, 37, 3308-3311.

285 A. T. Wright and E. V. Anslyn, Chem. Soc. Rev., 2006, 35, 14-28.

286 G. J. Havrilla and T. C. Miller, Rev. Sci. Instrum., 2005, 76.

287 O. Birkert, R. Tunnernann, G. Jung and G. Gauglitz, Anal. Chem., 2002, 74, 834-840.

288 P. Chojnacki, T. Werner and O. S. Wolfbeis, Microchim. Acta, 2004, 147, 87-92.

289 A. Apostolidis, I. Klimant, D. Andrzejewski and O. S. Wolfbeis, J. Comb. Chem., 2004, 6, 325-331.

290 A. W. Schwabacher, C. W. Johnson and P. Geissinger, Macromol. Rapid Commun., 2004, 25, 108-118.

291 I. Lundstrom, Nature, 2000, 406, 682-683.

292 M. Stopfer, V. Jayaraman and G. Laurent, Neuron, 2003, 39, 991-1004.

293 N. A. Rakow and K. S. Suslick, MRS Bull., 2004, 29, 913.

294 T. A. Dickinson, J. White, J. S. Kauer and D. R. Walt, Trends Biotechnol., 1998, 16, 250-258.

295 A. Goodey, J. J. Lavigne, S. M. Savoy, M. D. Rodríguez, T. Curey, A. Tsao, G. Simmons, J. Wright, S. J. Yoo, Y. Sohn, E. V. Anslyn, J. B. Shear, D. P. Neikirk and J. T. McDevitt, J. Am. Chem. Soc., 2001, 123, 2559-2570. 
296 C. M. Bishop, Neural Networks for Pattern Recognition, Oxford University Press Inc., New York, 2004.

297 W. B. Lyons and E. Lewis, Trans. Instrum. Meas. Control, 2000, 22, 385-404.

298 K. Persaud and G. Dodd, Nature, 1982, 299, 352-355.

299 K. J. Albert, N. S. Lewis, C. L. Schauer, G. A. Sotzing, S. E. Stitzel, T. P. Vaid and D. R. Walt, Chem. Rev., 2000, 100, 2595-2626.

300 D. James, S. M. Scott, Z. Ali and W. T. O'Hare, Microchim. Acta, 2005, 149, 1-17.

301 T. A. Dickinson, J. White, J. S. Kauer and D. R. Walt, Nature, 1996, 382, 697-700.
302 P. Pantano and D. R. Walt, Chem. Mater., 1996, 8, 2832-2835.

303 J. M. Tam, L. N. Song and D. R. Walt, Talanta, 2005, 67, 498-502.

304 K. Wygladacz and E. Bakker, Anal. Chim. Acta, 2005, 532, 61-69.

305 J. R. Epstein, J. A. Ferguson, K. H. Lee and D. R. Walt, J. Am. Chem. Soc., 2003, 125, 13753-13759.

306 I. Biran, D. M. Rissin, E. Z. Ron and D. R. Walt, Anal. Biochem., 2003, 315, 106-113.

307 T. Mayr, C. Igel, G. Liebsch, I. Klimant and O. S. Wolfbeis, Anal. Chem., 2003, 75, 4389-4396.

308 M. Gao, L. M. Dai and G. G. Wallace, Electroanalysis, 2003, 15, 1089-1094.

\section{Find a SOLUTION ... with books from the RSC}

\section{Choose from exciting textbooks, research level books or reference books in a wide range of subject areas, including:}

- Biological science

- Food and nutrition

- Materials and nanoscience

- Analytical and environmental sciences

- Organic, inorganic and physical chemistry

\section{Look out for 3 new series coming soon ...}

- RSC Nanoscience \& Nanotechnology Series

- Issues in Toxicology

- RSC Biomolecular Sciences Series

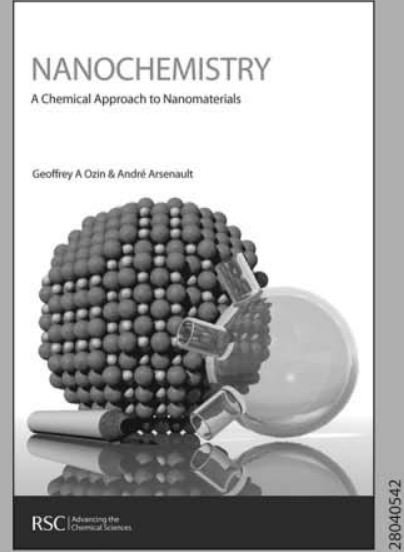

www.rsc.org/books 